\title{
Performance of satellite-based and GPCC 7.0 rainfall products in an extremely data-scarce country in the Nile Basin
}

DOI:

10.1016/j.atmosres.2018.08.028

\section{Document Version}

Accepted author manuscript

Link to publication record in Manchester Research Explorer

Citation for published version (APA):

Basheer, M., \& Elagib, N. A. (2019). Performance of satellite-based and GPCC 7.0 rainfall products in an extremely data-scarce country in the Nile Basin. Atmospheric Research, 215, 128-140.

https://doi.org/10.1016/j.atmosres.2018.08.028

Published in:

Atmospheric Research

\section{Citing this paper}

Please note that where the full-text provided on Manchester Research Explorer is the Author Accepted Manuscript or Proof version this may differ from the final Published version. If citing, it is advised that you check and use the publisher's definitive version.

\section{General rights}

Copyright and moral rights for the publications made accessible in the Research Explorer are retained by the authors and/or other copyright owners and it is a condition of accessing publications that users recognise and abide by the legal requirements associated with these rights.

\section{Takedown policy}

If you believe that this document breaches copyright please refer to the University of Manchester's Takedown Procedures [http://man.ac.uk/04Y6Bo] or contact uml.scholarlycommunications@manchester.ac.uk providing relevant details, so we can investigate your claim.

\section{OPEN ACCESS}


Performance of satellite-based and GPCC 7.0 rainfall products in an extremely datascarce country in the Nile Basin

$$
\text { Mohammed Basheer }{ }^{1,2} \text { and Nadir Ahmed Elagib }{ }^{1 * *}
$$

${ }^{1}$ Institute for Technology and Resources Management in the Tropics and Sub-tropics (ITT), Technische Hochschule Köln, Betzdorferstr. 2, 50679, Cologne, Germany

*Corresponding author's email: elagib@hotmail.com; nadir.elagib@th-koeln.de

${ }^{2}$ Email address: mohammedadamabbaker@gmail.com; mohammed.basheer@th-koeln.de 


\section{Highlights}

- GPCC 7.0 and five satellite-based rainfall products versus station rainfall for South Sudan

- Monthly and annual data from GPCC 7.0 followed by CHIRPS v2.0 agree best with station rainfall

- Capturing the variability in maximum monthly rainfall is attained best by ARC2 then by GPCC 7.0.

- The studied satellite-based rainfall products under-estimate the maximum monthly rainfall

- This study helps improve the rainfall database for the country, but enhancing the station network is imperative

\section{Abstract}

The rain gauge networks in the African countries are notorious for their poor density and low frequency of observations. Rainfall estimates derived from satellites have proven to be a viable alternative in the recent evolving campaigns to overcome this deficiency. The newly-borne country within the Nile Basin, South Sudan, has extremely few operating rain gauge stations. Herein, evaluation of six long-term (1983 onward) rainfall estimates, i.e. the Global Precipitation Climatology Centre full data reanalysis version 7.0 (GPCC 7.0) and five Satellite-Rainfall Products (SRPs), is undertaken. Data from the only currently operating longterm stations (five) with reasonably up-to-date records are used to conduct point-to-pixel evaluation for the six products (from 1983 to 2010). The results of error and linear fit metrics rank GPCC 7.0 as the best performing product on monthly, maximum monthly, and annual scales, followed by Climate Hazards group Infrared Precipitation with Stations version 2.0 (CHIRPS v2.0). As regards the variability of annual rainfall, GPCC 7.0 outperforms the products whereas the Precipitation Estimation from Remotely Sensed Information Using Artificial Neural Networks-Climate Data Record (PERSIANN-CDR) and CHIRPS v2.0 have 
the second-best performance. GPCC 7.0 and the Multi-Source Weighted-Ensemble Precipitation version 2.0 (MSWEP 2.0) show better agreement of variability of monthly rainfall with that of the station rainfall. The Africa Rainfall Climatology version 2.0 (ARC2) performs the best in capturing the variability in the maximum monthly rainfall followed by GPCC 7.0. In relation to capturing the median rainfall, a complex performance is evident across the stations with the following remarks: relatively good performance from MSWEP 2.0 on the annual scale followed by PERSIANN-CDR; GPCC 7.0 (PERSIANN-CDR) is mostly (relatively) operational for the median maximum monthly rainfall; GPCC 7.0 (CHIRSPS v2.0) is mostly (partly) suitable as an estimator for the monthly median. All the present SRPs unequivocally under-estimate the monthly peaks. Enhancing the rainfall estimation and observation network is key to improving the understanding and modeling of the hydrological processes and phenomena occurring in the basin in general and in the floodplains of the country in particular.

Keywords: Rainfall; Satellite-based rainfall; Data scarcity; Nile Basin, Africa; South Sudan

\section{Introduction}

Rainfall is recognized as the main element that influences livelihoods in many developing countries, especially those depending primarily on agriculture to support their economies. There is a fundamental concern about the precise estimation of the quantity and timing of rainfall (Ciach, 2003) for water resources studies, such as hydrological modeling, water balance calculations, etc. (Faurès et al., 1995; Obled et al., 1994; Potter et al., 2005). Nevertheless, rainfall monitoring suffers considerable disregard in many developing countries. Furthermore, ground rain gauges in most developing countries are limited in number compared 
to the areas they cover (low gauge to area ratios), poorly distributed, and have gaps in their records (Dinku et al., 2007; Fuka et al., 2014; Hughes, 2006).

Many climate investigators have addressed the issue of poorly distributed and degrading number of rain gauge networks in Africa (e.g. Nicholson, 1985; Hulme, 1990; Elagib, 2011; Mahmoud et al., 2014; Tarnavsky et al., 2014; Awange et al., 2016; Mahmood et al., 2017). In addition to the poor spatial coverage of rain gauge networks, records of diurnal rainfall are very scarce (Rientjes et al., 2013). This inherent situation exists even within large and most physically, socially, and politically complex basins (Romilly and Gebremichael, 2011; Worqlul et al., 2014; Abera et al., 2016; Basheer and Elagib, 2018). According to Washington et al. (2006), one of the main reasons currently curtailing the progress in climate science in Africa is the lack of "reliable, long-term, and well-distributed climate information". Thomson et al. (2011) argue that the availability of relevant and reliable climate data and services can reduce the extreme vulnerability to, and inform the management of, climaterelated diseases in Africa. Climate information can also strengthen the long-term ability to address the consequences of climate variability and change (Dilley, 2000; Washington et al., 2006) and, ultimately, serve development in low-income regions (Tall, 2010).

In the quest for improving the rainfall measuring networks in Africa, several studies on evaluating the performance of Satellite-based Rainfall Products (SRPs) have been conducted within the African continent on different spatial and temporal scales. Serrat-Capdevila et al. (2016) evaluated the performance of three SRPs over the entire Africa using the Global Precipitation Climatology Project one Degree Day (GPCP-1dd) as a comparison benchmark. They found that the Tropical Rainfall Measuring Mission (TRMM) Multi-satellite Precipitation Analysis (TMPA-3B42RT) performs the best in capturing precipitation quantities over South Sudan compared to Precipitation Estimation from Remotely Sensed Information using Artificial Neural Networks (PERSIANN) and the U.S. National Weather Service Climate 
Prediction Centre (CPC) Morphing Technique (CMORPH). Using rainfall records from six ground stations, another study assessed the accuracy of CMORPH and the Tropical Rainfall Measuring Mission (TRMM) Multi-satellite Precipitation Analysis research-grade product (TMPA-3B42) over the Nile basin (Habib, 2012). The study revealed under- and overestimation by the two products over the majority of the Nile Basin depending on the topography and the latitude. Basheer et al. (2018) evaluated the daily performance of Precipitation Estimation from Remotely Sensed Information Using Artificial Neural Networks-Climate Data Record (PERSIANN-CDR), Tropical Applications of Meteorology Using Satellite Data and Ground-Based Observations version 2.0 (TAMSAT-2), Africa Rainfall Climatology Version 2.0 (ARC2), and Climate Hazards group Infrared Precipitation with Stations version 2.0 (CHIRPS 2.0) over the Blue Nile Basin and concluded that ARC2 has the best overall performance. Other studies evaluated some SRPs over relatively smaller river basins, such as Zambezi, Volta, Juba-Shabelle, Baro-Akobo, Kafue, Thukela, and Kat (Serrat-Capdevila et al., 2016; Thiemig et al., 2012). Many studies have been conducted for specific regions, such as the Ethiopian highlands (Dile and Srinivasan, 2014; Dinku et al., 2007; Diro et al., 2009; Young et al., 2014), western Uganda (Diem et al., 2014), and western Africa (Dembélé and Zwart, 2016; Roca et al., 2010).

A striking example of African countries where climate observations are extremely scanty is South Sudan, the newly borne African country in 2011 and one of the Nile Basin countries. Despite encompassing one of the Africa's largest wetlands and due to political unrest and civil war before its separation from the Republic of Sudan, many stations in South Sudan have either been shut down or suffered gaps in their records (Mohamed et al., 2006; Elagib and Mansell, 2000a; Elagib, 2010). Hence, the use of SRPs provides insight into the temporal evolution of the hydro-meteorological parameters to understand the physical situation exhibited by land surface-climate interactions and the embedded feedbacks of the floodplains 
(Mohamed et al., 2006). In line with this, satellite remote sensing offers products for precipitation retrievals, application in hydrology and water cycle studies, gaining insights into precipitation events and process, climate change studies, etc. (Kidd and Levizzani, 2011). Interest in the quantification of rainfall is essential for the wetlands of South Sudan, in which the high evaporation and transpiration in drier months (Alvi and Elagib, 1996; Sutcliffe and Parks, 1999) contribute to local precipitation (Eagleson, 1986; Eltahir, 1989), termed precipitation recycling (Eltahir and Bras, 1994).

With the above background, the purpose of this paper is to evaluate the performance of five long-term (> 30 years of record) SRPs over South Sudan including PERSIANN-CDR, TAMSAT-2, ARC2, CHIRPS v2.0, and dataset and Multi-Source Weighted-Ensemble Precipitation version 2.0 (MSWEP 2.0). Moreover, the performance of the Global Precipitation Climatology Centre full data reanalysis version 7.0 (GPCC 7.0), which is a gauge-based rainfall product, is also evaluated. The evaluation is carried out over the period 1983 to 2010 using the available ground observations from five rainfall stations. This study is hoped to enhance the spatial coverage of rainfall estimates for the country.

\section{Study area}

The Republic of South Sudan (Fig. 1) is a newly-born country. Based on a peace agreement signed between the Government of Sudan and the Sudan People's Liberation Movement (SPLM) to put an end for a civil war that started as early as 1955, the independence of the country was enabled as a result of a self-determination referendum conducted in the year 2011 (Salman, 2011). South Sudan is located in Central East Africa and has an area of around $630,000 \mathrm{~km}^{2}$. It is landlocked and shares borders with six countries, including Sudan, Ethiopia, Kenya, Uganda, Democratic Republic of the Congo, and Central African Republic (see Fig. 1). Gentle slope towards the North East characterizes the topography of South Sudan. While the 
altitude ranges between 360 and 3175 masl, more than $80 \%$ of the total area falls below 600 masl.

The study area has climate conditions ranging from semi-arid to sub-humid (Elagib, 2002). The mean monthly temperature falls within a range of 25 to $32^{\circ} \mathrm{C}$ (Elagib and Mansell, 2000b) whereas the annual rainfall can take the range of 400 to as high as $1300 \mathrm{~mm}$, occurring respectively in the northern-most part and the farthest southwestern area. Around $97 \%$ of the area of South Sudan is located in the Nile Basin. The presence of the vast Sudd swamps (see Fig. 1) are responsible for substantial evaporation and transpiration in the study area (Sutcliffe and Parks, 1999). Most of the Sudd water originates from the equatorial lakes in Burundi, Democratic Republic of the Congo, Kenya, Rwanda, Tanzania, and Uganda (Sutcliffe and Parks, 1999). It is estimated that only $50 \%$ of the inflow to the swamps continues downstream to Sudan (Wheeler et al., 2016).

\section{Data and methods}

\subsection{Rainfall data}

The rainfall monitoring network of South Sudan experienced considerable deterioration over time due to prolonged and renewed civil wars. Out of 14 rainfall stations used by Hulme (1990), only five long-term ones (Fig. 1) were still operating until the country's independence took place in mid-2011. The other nine stopped recording some time around the beginning of the 1980s. The five operating rain gauges constituted the source of ground-based (reference) data for the present study and were obtained from Sudan Meteorological Authority. The five stations are part of the Global Telecommunication Network (GTS), but their records were reported intermittently. Even though the GTS rainfall data are used as an input to some of the evaluated products, we believe that the five stations can still be used as a comparison benchmark because station data are not the sole input to some of the products. Moreover, the 
intermittency in reporting the stations' records to GTS is another factor justifying their use. Of the five stations, Malakal and Er Renk are in a semi-arid climatic zone, Juba and Wau are in a dry sub-humid zone, and Raja is in a sub-humid zone (Elagib, 2002). The five stations had record length for this study over 1983-2010 except Raga, which had data until 1999 due to largely missing records thereafter. Very few missing monthly records in the station datasets were filled in by taking the average of six records for the same month from three preceding and three succeeding years in the time series. An exception to this approach was adopted in case the missing data did not lie in the middle of the six records, wherein the average of the nearest six records was considered. towards the beginning and/or the end of the record length This gapfilling approach was suggested by Qureshi and Khan (1994) and was also adopted by Elagib and Mansell (2000b). Our evaluation focused on monthly, annual, and maximum monthly rainfall for the period 1983 onward, depending on the availability of ground records. Point-topixel evaluation was chosen for this study because it suits regions with limited ground stations.

Due to the vital need for a long-term rainfall record, some SRPs that cover South Sudan with a record length of at least 30 years were evaluated in this study. The SRPs evaluated herein include the African Rainfall Climatology Version 2 (ARC2: Novella and Thiaw, 2013), the Climate Hazards group InfraRed Precipitation with Station data version 2 dataset (CHIRPSv2.0: Funk et al. (2014)), Multi-Source Weighted-Ensemble Precipitation version 2.0 (MSWEP 2.0: Beck et al. (2017)), Precipitation Estimation from Remotely Sensed Information using Artificial Neural Networks-Climate Data Record (PERSIANN-CDR: Ashouri et al. (2015)), and the Tropical Applications of Meteorology using Satellite and ground-based observations (TAMSAT-2: (Maidment et al. (2017)). Furthermore, a long-term rainfall product, i.e. the Global Precipitation Climatology Centre full data reanalysis version 7.0 (GPCC 7.0: Schneider et al. (2015)) was also evaluated in this study. 
ARC2 is developed by the Climate Prediction Center (CPC) of the National Oceanic and Atmospheric Administration (NOAA). The following information on the product is given by Novella and Thiaw (2013). It provides daily rainfall estimates over Africa at $0.1^{\circ} \times 0.1^{\circ}$ (around $10 \mathrm{~km} \times 10 \mathrm{~km}$ ) spatial resolution for the period 1983 to near-present. ARC2 is developed based on two inputs: (1) rainfall observations from ground gauges and (2) InfraRed geostationary satellite imagery. The first input comes from the daily ground rainfall record of the Global Telecommunication System (GTS) gauge network operated by the World Meteorological Organization (WMO). GTS receives daily rainfall observations from around 1,200 ground gauges in Africa. The second input includes 3-hourly IR satellite imagery from Meteosat First Generation Satellites 2-7 (MFG-2-7) for the period 1983 to 2005, and from Meteosat Second Generation (MSG) for the period 2006 to date. ARC2 contains 341 missing values (data gap) in the period from January 1983 to March 2018 (2.65\% data gap). Of these missing data, 340 missing values lie in the evaluation period of this study (3.32\% data gap), as reported by CPC (2018). These were filled similar to the approach used above with ground station data.

CHIRPS v2.0 is developed by the U.S. Geological Survey (USGS) and the Climate Hazards Group of the University of California (Funk et al., 2014). With a spatial resolution of $0.05^{\circ} \times 0.05^{\circ}$ (around $5.3 \mathrm{~km} \times 5.3 \mathrm{~km}$ ), it provides global daily, pentadal, and monthly rainfall estimates between $50^{\circ} \mathrm{S}$ and $50^{\circ} \mathrm{N}$ for the period 1981 to near-present (Funk et al., 2014). Funk et al. (2015) reports the following information on this product. CHIRPS v2.0 is a blended product that includes IR satellite imagery and gauge observations. It utilizes two sources of IR satellite imagery, the Globally Gridded Satellite (GridSat) dataset of the National Climate Center of NOAA for the period 1981 to 2008, and the dataset of the Climate Prediction Center (CPC TIR) of NOAA for the period 2000 to present. The overlap period (2000 to 2008) is used to remove the systematic difference between the two IR imagery sources. Gauge observations 
that are used as input to CHIRPS come from several sources including the Global Historical Climate Network (GHCN), Global Summary of the Day (GSOD), GTS, Southern Africa Service Centre for Climate Change and Adaptive Land Management (SASSCAL), in addition to national meteorological agencies from Mexico, Central America, South America, and SubSaharan Africa. It is worth mentioning that the number of stations in Africa that are used in developing CHIRPS v2.0, excluding the ones from the Republic of South Africa, has declined from around 2400 for the 1980 s to around 500 post-2010.

MSWEP 2.0 is a rainfall product developed by Princeton University to provide 3-hourly global rainfall estimates for the period 1979 to 2016 at $0.1^{\circ} \times 0.1^{\circ}$ (around $10 \mathrm{~km} \times 10 \mathrm{~km}$ ) spatial resolution (Beck et al., 2017). MSWEP 2.0 incorporates inputs from four sources: ground observations that come from GHCN, GSOD, the Latin American Climate Assessment and Dataset (LACAD), Chile climate data library, and national databases from Iran, Brazil, Mexico, and Peru; satellite observations including CMORPH, the gridded satellite (GridSat), Global Satellite Mapping of Precipitation (GSMap), Tropical Rainfall Measuring Mission (TRMM) Multi-Satellite Precipitation Analysis product (TMPA 3B42RT); reanalysis rainfall products including the European center for medium-range weather forecasts ReAnalysis Interim (ERAInterim) and the Japanese 55-year ReAnalysis (JRA-55); and GPCC 7.0 (Beck, 2017).

PERSIANN-CDR is developed by the National Climatic Data Center (NCDC) of NOAA to provide daily rainfall estimates for the globe between $60^{\circ} \mathrm{S}$ and $60^{\circ} \mathrm{N}$ for the period 1983 to near-present at a $0.25^{\circ} \times 0.25^{\circ}$ spatial resolution (around $27 \mathrm{~km} \times 27 \mathrm{~km}$ ) (Ashouri et al., 2015; Miao et al., 2015). PERSIANN-CDR is developed using an artificial neural network model. The National Centers for Environment Prediction (NCEP) stage IV hourly precipitation data are used to pre-train the model and to determine its parameters. Then IR imagery from GridSat is applied as an input to run the model, and the Global Precipitation Climatology 
Project (GPCP) monthly product is used for bias-correction of the outputs (Ashouri et al., 2015).

TAMSAT-2, developed by the University of Reading, provides daily rainfall estimates from 1983 to near-present (Maidment et al., 2017). The TAMSAT-2 dataset encompasses only the African continent with a $0.0375^{\circ} \times 0.0375^{\circ}$ (around $4 \mathrm{~km} \times 4 \mathrm{~km}$ ) spatial resolution, with inputs from Meteosat IR imagery from the European Organization for the Exploitation of Meteorological Satellites (EUMETSAT) and rainfall data from gauges for its development (Maidment et al., 2014; Tarnavsky et al., 2014). The IR satellite imagery was acquired every 30 minutes until June 2006 and every 15 minutes thereafter (Tarnavsky et al., 2014).

Lastly, GPCC 7.0 was developed by the Global Precipitation Climatology Centre (GPCC), which is operated by Deutscher Wetterdienst (DWD, National Meteorological Service of Germany) (Schneider et al., 2015). GPCC 7.0 provides global monthly rainfall estimates for the period 1901 to 2013, which are solely based on ground observations from around 75100 stations worldwide that feature at least 10 years of records, at $0.5^{\circ} \times 0.5^{\circ}$, $1.0^{\circ} \times 1.0^{\circ}$ and $2.5^{\circ} \times 2.5^{\circ}$ spatial resolutions (Schneider et al., 2016). The present study used the GPCC 7.0 product with a $0.5^{\circ} \times 0.5^{\circ}$ spatial resolution.

The freely accessible programming language $\mathrm{R}$ ( $\mathrm{R}$ Core Team, 2015) was used to download the rainfall products, extract the pixel values at the locations of the ground gauges, aggregate the values into monthly and/or annual, and derive the maximum monthly time series.

\subsection{Evaluation of rainfall products}

To measure the discrepancy between the observed and estimated monthly, annual, and maximum monthly rainfall, three error and three linear fit metrics were used, including the Root Mean Square Error (RMSE: Eq. 1), the Mean Absolute Bias Error (MABE: Eq. 2), the Mean Bias Error (MBE: Eq. 3), the coefficient of determination (R²: Eq.4), and the slope (Eq. 
5) and the intercept (Eq. 6) of the regression line. Moreover, two statistical measures were calculated for the observations and the estimates of monthly, annual, and maximum monthly rainfall, and were used in the comparison. These are the coefficient of variation (CV: Eq. 7), i.e. a measure of dispersion, and the median (M), i.e. a measure of central tendency. There are two reasons for the choice of $M$ instead of the mean. First, $M$ is a better measure of central tendency in conditions of variable rainfall and, second, the mean is already embedded in the calculation of $\mathrm{CV}$.

$$
\begin{aligned}
& \operatorname{RMSE}(\mathrm{mm})=\sqrt{\frac{1}{n} \sum_{i=1}^{n}\left(S_{i}-G_{i}\right)^{2}} \\
& \operatorname{MABE}(\mathrm{mm})=\frac{1}{n} \sum_{i=1}^{n}\left|S_{i}-G_{i}\right| \\
& \operatorname{MBE}(\mathrm{mm})=\frac{1}{n} \sum_{i=1}^{n}\left(S_{i}-G_{i}\right) \\
& \mathrm{R}^{2}=\frac{\left(n\left(\sum_{i=1}^{n} G_{i} S_{i}\right)-\left(\sum_{i=1}^{n} G_{i}\right)\left(\sum_{i=1}^{n} S_{i}\right)\right)^{2}}{\left(n\left(\sum_{i=1}^{n} G_{i}{ }^{2}\right)-\left(\sum_{i=1}^{n} G_{i}\right)^{2}\right)\left(n\left(\sum_{i=1}^{n} S_{i}{ }^{2}\right)-\left(\sum_{i=1}^{n} S_{i}\right)^{2}\right)} \\
& \text { Slope }=\frac{\left(\sum_{i=1}^{n} G_{i} S_{i}\right)-\frac{\left(\sum_{i=1}^{n} G_{i}\right)\left(\sum_{i=1}^{n} S_{i}\right)}{n}}{\left(\sum_{i=1}^{n} G_{i}{ }^{2}\right)-\frac{\left(\sum_{i=1}^{n} G_{i}\right)^{2}}{n}} \\
& \operatorname{Intercept}(\mathrm{mm})=\bar{S}-S \operatorname{Slope} \times \bar{G} \\
& \operatorname{CV}(\%)=\frac{\sqrt{\frac{\sum_{i=1}^{n}\left(S_{i}-\bar{S}\right)}{n-1}}}{\bar{S}} \times 100
\end{aligned}
$$

Where $G_{i}$ is the ith gauge observation $(\mathrm{mm}), S_{i}$ is the ith rainfall estimate $(\mathrm{mm}), \mathrm{n}$ is number of data pairs, $\bar{G}$ is the mean of the gauge observations (mm), and $\bar{S}$ is the mean of the rainfall estimates $(\mathrm{mm})$. 
RMSE and MABE indicate the magnitude of the average discrepancy and range between zero (no error) and +o (high error). MBE marks out the direction of discrepancy bias and ranges between $-\infty$ and $+\infty$ (both indicate high error) with no error at zero. Negative MBE values signal overall underestimation of rainfall by the products and positive values indicate overestimation. $\mathrm{R}^{2}$ measures the correlation between the estimated and the observed values by explaining the ratio or percentage of variations in the dependent variable that could be explained by the predictor (the independent variable). It varies from zero (no correlation) to 1 (total correlation). The Slope and the Intercept indicate the systematic error in the estimates of the rainfall products. The Slope can take any value from $-\infty$ to $+\infty$ (both indicate misestimation), but with a value of 1 for the perfect estimation. Similarly, the Intercept ranges from $-\infty$ to $+\infty$ (both indicate misestimation), but with the exact estimation giving a value of zero. CV measures the relative variability and can take any value from zero (no variability) to $+\infty$ (high variability).

To draw overall conclusions on the performance of the rainfall products in estimating the monthly, annual, and maximum monthly rainfall amounts at the different evaluation stations, an approach based on summing up the performance rankings (Elagib and Mansell, 2000c) was adopted herein for each rainfall product according to each error and linear fit metric and at each evaluation location (i.e. rainfall station). This metric is referred to herein as Unified Metric (UM: Eq.8). That gives an indication of the most accurate product at each evaluation location. Also, we calculated an Overall UM (OUM: Eq. 9) for each product based on the sum of the UMs at different evaluation stations. UM ranges from 6 to 36, i.e. respectively from the number of the evaluated rainfall products to the number of the evaluated rainfall products multiplied by the number of error and linear fit metrics. On the other hand, OUM varies from 30 to 180 , i.e. respectively from the number of the evaluated rainfall products multiplied by the number of the evaluation locations to the number of the evaluated rainfall products multiplied 
by the number of error and linear fit metrics multiplied by the number of the stations. Low UM and OUM values show that the rainfall product performs well compared with the other rainfall products under evaluation.

$\mathrm{UM}_{r j}=\sum_{i=1}^{p} R_{r j i}$

$\mathrm{OUM}_{r}=\sum_{j=1}^{e} \mathrm{UM}_{r j}$

where $\mathrm{UM}_{r j}$ is the Unified Metric of the rainfall product $r$ at the station $\mathrm{j}, p$ is the number of performance metrics, $R_{r j i}$ is the performance ranking of the rainfall product $r$ at the station $j$ based on the performance metric $i, \mathrm{OUM}_{r}$ is the Overall Unified Metric of the rainfall product $r, e$ is the number of stations, $\mathrm{UM}_{r j}$ is the Unified Metric of the rainfall product $\mathrm{r}$ at the station $j$.

\section{Results and discussion}

\subsection{Performance based on error and linear fit metrics}

Figs. 2-4 present the six error and linear fit performance metrics for the five stations calculated for the monthly, annual, and maximum monthly rainfall amounts, respectively. It can be noticed that the six metrics show varying performance among the products as well as the stations. However, the variation is more pronounced among the former than the latter. The case of monthly rainfall given in Fig. 2 reveals that, based on the five-station average performance metric, GPCC 7.0 has the most accurate estimates followed by CHIRPS v2.0. Contrarily, ARC2 emerge as the least accurate among the six products. Concerting with the previous case, GPCC 7.0 demonstrates superior performance on annual basis (Fig. 3), indicated by lowest intercept (nearest to zero), nearest slope to 1.0, highest $\mathrm{R}^{2}$ and smallest errors (MBE, MABE, and RMSE). CHIRPS v2.0 show the second-best performance in capturing the annual rainfall as measured by five out of six indicators (the slope ranks the product third). Again, 
ARC2 is ranked last on annual basis. Based on the five-station average of the performance metrics for the maximum monthly rainfall (Fig. 4), GPCC 7.0 demonstrates superiority among the six products, followed by CHIRPS v2.0 though the MBE ranks it fifth. Moreover, MSWEP 2.0 shows the fifth-best performance followed by TAMSAT-2, which has the worst performance based on four out of the six metrics.

The values of the MBE in monthly rainfall (see Fig. 2) reveal varying under- and overestimation characteristics of the products in producing the monthly gauge observations. PERSIANN-CDR and TAMSAT-2 are characterized by over- and under-estimation at all the stations, respectively, with an average bias of 5.7 and $-9.4 \mathrm{~mm}$. ARC2 and CHIRPS v2.0 respectively over- and under-estimate the monthly rainfalls at four out of five stations. The magnitude of bias averaged over the five stations is found to be 4.3 and $-2.7 \mathrm{~mm}$, respectively. Moreover, GPCC 7.0 has a five-station average bias of $1.9 \mathrm{~mm}$ in estimating the monthly rainfall. On annual basis (Fig. 3), the five-station average MBE values range from $-111.0 \mathrm{~mm}$ in the case of TAMSAT-2 to $70.3 \mathrm{~mm}$ in the case of PERSIANN-CDR. The best product (GPCC 7.0) shows an average bias error of $28.7 \mathrm{~mm}$ in estimating the annual. As for the maximum monthly rainfall (Fig. 4), the five-station average MBE varies from $-0.1 \mathrm{~mm}$ (GPCC 7.0) to $-65.9 \mathrm{~mm}$ (TAMSAT-2), thus predominantly indicating overall under-estimation by the SRPs. The use of IR imagery as a primary input without including microwave imagery could be the main reason behind this underestimation behavior (see Section 3.1 for information about the inputs of the SRPs). Whereas IR rainfall retrievals are known to capture convective rainfall from cold clouds well, they fail to capture local heavy rainfall associated with warm clouds (e.g. in coastal and mountainous areas) as discussed by Maidment et al. (2017) and by Novella and Thiaw (2013). The poor performance of TAMSAT-2 in capturing the maximum monthly rainfall (five-station average MBE of $-65.9 \mathrm{~mm}$ ) could be, additionally, explained by the calibration target of the product. TAMSAT-2 was developed to monitor droughts and, 
therefore, was calibrated to capture low frequent rainfall amounts better, resulting in underestimating the total rainfall (Maidment et al., 2017). This attribute of TAMSAT-2 has been observed by several studies conducted for the neighboring country, Ethiopia (Dinku et al., 2007; Young et al., 2014). Moreover, the annual and monthly MBE values obtained with ARC2 show no pattern related to topography or climate - a result which contrasts with the findings by Diem et al. (2014), who evaluated the performance of ARC2 in Western Uganda. They found that ARC2 tends to underestimate (overestimate) the total rainfall amounts in wetter (drier) areas. Our results agree with the findings by Dembélé and Zwart (2016), who reported underestimation of the total rainfall amount in Burkina Faso by CHIRPS v2.0. Nevertheless, our analysis contrast with Young et al. (2014) and Dembélé and Zwart (2016) in underestimating the total rainfall amount in Ethiopia and Burkina Faso by ARC2.

Table 1 presents the UM and OUM for the rainfall products. The OUM values revealed the first three performance rankings of the products in the following order: GPCC7.0, CHIRPS v2.0, and PERSIANN-CDR for monthly, annual, and maximum rainfalls. In the bottom of the ranking $\left(6^{\text {th }}\right)$ lies ARC2 for the monthly and annual rainfall but TAMSAT-2 for the maximum monthly rainfall. Based on the aforementioned results, the scatterplots of rainfall for the product with the best performance quality (i.e. GPCC7.0) are displayed in Fig. 5. The $\mathrm{R}^{2}$ values shown in this figure indicate that the GPCC7.0 explains 78\% (Er Renk) to 95\% (Juba) of the variations in gauge monthly rainfall, 34\% (Er Renk) to 88\% (Juba) of the variation in gauge annual rainfall, and $24 \%$ (Raga) to $90 \%$ (Juba) in the variation in gauge maximum monthly rainfall. One can also note from the figure that, on average, the $\mathrm{R}^{2}$ is $89 \%$ at the monthly level, $65 \%$ at the annual level, and $58 \%$ for maximum monthly rainfall. A striking observation is the systematic over-estimation exhibited by GPCC7.0 at the station of Malakal. This overestimation is reflecetd by positive MBE values, as presented in Figs. 2-4. 


\subsection{Performance based on statistical measures of dispersion and central}

\section{tendency}

Fig. 6 shows the performance results based on the $\mathrm{CV}$ and $\mathrm{M}$ for the annual and maximum monthly data. Based on CV, GPCC 7.0 outperforms at three out of five stations in explaining the variability in the annual rainfall. These stations are Juba, Raga, and Wau. Next to this product comes PERSIANN-CDR, has the best performance at two stations, namely Er Renk and Malakal. CHIRPS v2.0 is rated second at three stations, namely Juba, Malakal, and Wau. TAMSAT-2 exhibits the poorest performance at all the stations. With regard the variability in the maximum monthly rainfall, $\mathrm{ARC} 2$ is ranked first at three stations (Er Renk, Malakal, and Raga) whereas GPCC 7.0 is ranked second at three out of five stations (Juba, Raga, and Wau). Similar results were reported by Funk et al. (2015) who found that CHIRPS v2.0 tended to underestimate the rainfall variance in southwest North America.

Regarding the median rainfall amount, no overall conclusion can be drawn on the performance of the products on the annual scale as each one reveals mixed results across the stations, thus suggesting ARC2 for Er Renk, MSWEP 2.0 for Juba and Raga, CHIRPS v2.0 for Malakal, and TAMSAT-2 for Wau. However, median annual values very close to station observations can be noted for Juba, Malakal, and Wau. The median annual obtained by ARC2 at Er Renk is higher by $+7.8 \%$ than that for the station whereas the MSWEP 2.0 median annual at Raga is $+4.7 \%$ higher than that observed at the station. The second-best performance is a characteristic of CHIRPSv2.0 at Er Renk, ARC2 at Juba, TAMSAT-2 at both Malakal and Raga, and GPCC 7.0 at Wau. It is surprising to notice poor performance of GPCC 7.0 in capturing the median annual rainfall in view of its good performance explained by $\mathrm{CV}$ and the error and linear fit metrics. The situation is clearer as concerning the median of the maximum monthly rainfall. Here, GPCC 7.0 outperforms at the three most humid stations, namely Raga, Wau, and Juba; nonetheless, an under-estimation of $11.2 \%$ of the median of the maximum 
monthly rainfall is notable for Wau. On the second rank comes PERSIANN-CDR with very slight under-estimation of the median of the maximum monthly rainfall at two stations (Malakal and Juba). At the bottom of the rank (6th) lies TAMSAT-2 with considerable underestimation at three stations (Juba, Malakal, and Raga). The median of the maximum monthly rainfall for the five SRPs showed underestimation at all stations. This underestimation could be due to the dependency of the five SRPs on IR imagery as explained earlier.

Fig. 7 presents the $\mathrm{CV}$ and $\mathrm{M}$ on monthly scale for all the products for all the stations. One can notice at a glance a wide variation in, and deviations between, the $\mathrm{CV}$ values during the dry period of the year (November to March). On the other hand, M shows a reversed situation. The CV results suggest that GPCC7.0 is the best product in capturing the variability in monthly rainfall at three stations, namely Er Renk, Juba during the second half of the wet season, and Wau. Similar performance can be noted for MSWEP 2.0 also at three stations, namely Juba during the start of the rainy season, Malakal, and Raga. The former product is ranked second in capturing the ground CV values at Malakal and Raga. Similarly, ARC2 is graded second for Er Renk and Juba. It is worth noting that at Malakal and Raga, where MSWEP 2.0 performed best, GPCC 7.0 is ranked second best. The results also suggest that TAMSAT-2 underperforms most notably in capturing the monthly CV values at the five stations.

On the other hand, the results on the median monthly rainfalls indicate GPCC 7.0 is best in estimating the median for Er Renk, Juba and, Raga while CHIRPS v2.0 follows at Juba and Raga. In the case of GPCC 7.0, the bias found for the three stations amounts to -1.5 to 3.4 $\mathrm{mm},-0.9$ to $3.9 \mathrm{~mm}$, and -4.4 to $10.9 \mathrm{~mm}$, respectively. At Malakal, ARC2 and CHIRPS v2.0 show very good performance during Jun to October, with a deviation of -22.2 to $9.8 \mathrm{~mm}$ and -10.2 to $12.4 \mathrm{~mm}$ respectively, while TAMSAT-2 also gives very close estimates during May to July with a bias of -5.4 to $3.8 \mathrm{~mm}$. At Malakal, ARC2, and CHIRPS v2.0 show very good 
performance from Jun to October while TAMSAT-2 also gives very close estimates from May to July. The products present mixed performance results for Wau. While MSWEP 2.0 is superior to other products during the first part of the rainy season (April to Jun), it is least performing during June to September. Further information on the distribution of the observed and estimated rainfall can be found in the supplementary material (Figs S1 to S10) which shows boxplots of monthly, annual, and maximum monthly rainfall.

\section{Conclusions}

Evaluation of the five SRPs, namely ARC2, CHIRPS v2.0, MSWEP 2.0, PERSIANNCDR and TAMSAT-2, and GPCC 7.0 against observations at five rainfall stations in South Sudan has been carried out for the period 1983 to 2010. The following conclusions can be noted:

a. In terms of rankings based on six error and linear fit metrics, GPCC 7.0 has been found to perform best on monthly, maximum monthly, and annual scales, followed by CHIRSPS v2.0. ARC2 exhibited the least performance on the monthly and annual scales while TAMSAT-2 has been ranked last at the maximum monthly level. All SRPs have shown a striking underestimation of the maximum monthly rainfall.

b. Further evaluation based on the coefficient of variation to measure the performance in terms of capturing the rainfall variability has shown outperformance of GPCC 7.0 and PERSIANN-CDR as regards the variability in the annual data. CHIRPS v2.0 has come in the second position. TAMSAT-2 has consistently exhibited the poorest correspondence with the five stations observations. GPCC 7.0 and MSWEP 2.0 have revealed better correspondence of monthly $\mathrm{CV}$ to station $\mathrm{CV}$ compared to other products. The results again suggest notable underperformance of TAMSAT-2 in capturing the 
monthly $\mathrm{CV}$ values at the five stations. Mostly, ARC2 captures the variability in the maximum monthly data whereas GPCC 7.0 is rated second.

c. The products have shown complex performance among the stations in relation to the median annual rainfall with relatively better performance exhibited by MSWEP 2.0 and TAMSAT-2. As regards the median maximum monthly rainfall, the best performance is mostly shown by GPCC 7.0, the second best by PERSIANN-CDR, and remarkably low quality by TAMSAT-2. It has been seen from the comparison that the median monthly rainfall estimates from GPCC 7.0 or CHIRSPS v2.0 represent the closest resemblance to those of the stations over part of the country, specifically Er Renk, Juba and, Raga for the former product and Juba and Raga for the latter product.

The above findings indicate that the performance of rainfall products to some extent can (1) vary spatially across the different climatic conditions, (2) depend on the rainfall aspects or indices considered in the analysis, and (3) depend on the criteria used to examine the performance quality. There is a need to improve the quality of estimates of the products, especially in this part of the world. Also, the meteorological authorities of the newly born South Sudan should work effectively to enhance the national rain gauge network that has deteriorated over time due to past prolonged and recently renewed civil wars and political unrest in the country. This study is a first attempt to finding alternative rainfall data sources for the country. Whereas the focus of the present study was on monthly and annual timescales, next step should be to extend this work to deal with higher resolution data, i.e. daily, and examine more products and more rainfall aspects and indices. Notwithstanding this coarse resolution, the results have shed light on useful rainfall products for future gap filling in the time series and/or extending the temporal span of the series to allow long-term analysis of rainfall-dependent climatological and hydrological processes and phenomena. 


\section{References}

Abera, W., Brocca, L., Rigon, R., 2016. Comparative evaluation of different satellite rainfall estimation products and bias correction in the Upper Blue Nile (UBN) basin. Atmospheric Research 178, 471-483.

Alvi, S.H., Elagib, N.A., 1996. Study of hydrology and drought in the flood region of Sudan. Water International 21(2), 76-82.

Ashouri, H., Hsu, K., Sorooshian, S., Braithwaite, D., Knapp, K., Cecil, D., Nelson, B., Prat, O., 2015. PERSIANN-CDR: Daily precipitation climate data record from multisatellite observations for hydrological and climate studies. Bulletin of the American Meteorological Society 96, 69-83. doi:10.1175/BAMS-D-13-00068.1

Awange, J.L., Ferreira, V.G., Forootan, E., Andam-Akorful, S.A., Agutu, N.O., He, X.F., 2016. Uncertainties in remotely sensed precipitation data over Africa. International Journal of Climatology 36(1), 303-323.

Basheer, M., Elagib, N.A., 2018. Sensitivity of Water-Energy Nexus to dam operation: A Water-Energy Productivity concept. Science of the Total Environment 616-617, 918926. Doi: $10.1016 /$ j.scitotenv.2017.10.228

Basheer, M., Wheeler, K.G., Ribbe, L., Majdalawi, M., Abdo, G., Zagona, E.A., 2018. Quantifying and evaluating the impacts of cooperation in transboundary river basins on the Water-Energy-Food nexus: The Blue Nile Basin. Science of the Total Environment. 630, 1309-1323. doi:10.1016/j.scitotenv.2018.02.249

Beck, H., 2017. MSWEP Version 2.1 documentation.

Beck, H., Van Dijk, A., Levizzani, V., Schellekens, J., Miralles, D., Martens, B., De Roo, A., 2017. MSWEP: 3-hourly $0.25^{\circ}$ global gridded precipitation (1979-2015) by merging gauge, satellite, and reanalysis data. Hydrology and Earth System Sciences 21, 589-615. doi:10.5194/hess-21-589-2017 
Ciach, G., 2003. Local random errors in tipping-bucket rain gauge measurements. Journal of Atmospheric and Oceanic Technology 20, 752-759. doi: 10.1175/15200426(2003)20<752:LREITB >2.0.CO;2

CPC, 2018. CPC list of dates of missing ARC2 data [WWW Document]. URL ftp://ftp.cpc.ncep.noaa.gov/fews/fewsdata/africa/arc2/ARC2_missing_dates.txt

Dembélé, M., Zwart, S., 2016. Evaluation and comparison of satellite-based rainfall products in Burkina Faso, West Africa. International Journal of Remote Sensing 37(17), 39954014.

Diem, J., Hartter, J., Ryan, S., Palace, M. (2014). Validation of Satellite Rainfall Products for Western Uganda. Journal of Hydrometeorology 15, 2030-2038.

Dile, Y., Srinivasan, R., 2014. Evaluation of CFSR climate data for hydrologic prediction in data-scarce watersheds: An application in the Blue Nile River Basin. Journal of the American Water Resources Association 50(5), 1226-1241.

Dilley, M., 2000. Reducing vulnerability to climate variability in Southern Africa: the growing role of climate information. Climatic Change 45, 63-73.

Dinku, T., Ceccato, P., Grover-Kopec, E., Lemma, M., Connor, S., Ropelewski, C., 2007. Validation of satellite rainfall products over East Africa's complex topography. International Journal of Remote Sensing 28(7), 1503-1526.

Diro, G., Grimes, D., Black, E., O’Neill, A., Pardo-Iguzquiza, E., 2009. Evaluation of reanalysis rainfall estimates over Ethiopia. International Journal of Climatology 29(1), $67-78$.

Eagleson, P.S., 1986. The emergence of global-scale hydrology. Water Resources Research $22(9), 6 s-14 s$.

Elagib, N.A., Mansell, M.G., 2000a. Climate impacts of environmental degradation in Sudan. GeoJournal 50(4), 311-327. 
Elagib, N.A., Mansell, M.G., 2000b. Recent trends and anomalies in mean seasonal and annual temperatures over Sudan. Journal of Arid Environments 45(3), 263-288.

Elagib, N.A., Mansell, M.G., 2000c. New approaches for estimating global solar radiation across Sudan. Energy Conversion and Management 41(5), 419-434.

Elagib, N.A., 2002. Simulation of climate change effects on crop actual evapotranspiration over Sudan. In: V.P. Singh, M. Al-Rashed and M.M. Sherif (Editors). Surface Water Hydrology (Proceedings of the International Conference on Water Resources Management in Arid Regions (WaRMAR), Volume 1, Swets and Zeitlinger B.V., Lisse, The Netherlands, pp. 107-137.

Elagib, N.A., 2010. Trends in intra-and inter-annual temperature variabilities across Sudan. Ambio 39(5-6), 413-429.

Elagib, N.A., 2011. Changing rainfall, seasonality and erosivity in the hyper-arid zone of Sudan. Land Degradation \& Development 22(6), 505-512.

Eltahir, E.A.B., 1989. A feedback mechanism in annual rainfall in central Sudan. Journal of Hydrology 110, 323-334.

Eltahir, E.A., Bras, R.L., 1994. Precipitation recycling in the Amazon basin. Quarterly Journal of the Royal Meteorological Society 120(518), 861-880.

Faurès, J., Goodrich, D., Woolhiser, D., Sorooshian, S., 1995. Impact of small-scale spatial rainfall variability on runoff modeling. Journal of Hydrology 173(1-4), 309-326.

Fuka, D., Walter, M., Macalister, C., Degaetano, A., Steenhuis, T., Easton, Z., 2014. Using the Climate Forecast System Reanalysis as weather input data for watershed models. Hydrological Processes 28(22), 5613-5623.

Funk, C., Peterson, P., Landsfeld, M., Pedreros, D., Verdin, J., Rowland, J., Romero, B., Husak, G., Michaelsen, J., Verdin, A., 2014. A Quasi-Global Precipitation Time Series for Drought Monitoring. U.S. Geological Survey Data Series. 832, 4. 
doi:http://dx.doi.org/110.3133/ds832

Funk, C., Peterson, P., Landsfeld, M., Pedreros, D., Verdin, J., Shukla, S., Husak, G., Rowland, J., Harrison, L., Hoell, A., Michaelsen, J., 2015. The climate hazards infrared precipitation with stations - a new environmental record for monitoring extremes. Scientific Data 2. doi:10.1038/sdata.2015.66

Habib, E., Elsaadani, M., Haile, A., 2012. Climatology-Focused evaluation of CMORPH and TMPA satellite rainfall products over the Nile Basin. Journal of Applied Meteorology and Climatology 51, 2105-2121.

Hulme, M., 1990. The changing rainfall resources of Sudan. Transactions of the Institute of British Geographers 15(1), 21-34.

Hughes, D., 2006. Comparison of satellite rainfall data with observations from gauging station networks. Journal of Hydrology 327(3-4), 399-410.

Kidd, C., Levizzani, V., 2011. Status of satellite precipitation retrievals. Hydrology and Earth System Sciences 15(4), 1109-1116.

Mahmood, M.I., Elagib, N.A., Horn, F., Saad, S.A.G., 2017. Lessons learned from Khartoum flash flood impacts: An integrated assessment. Science of the Total Environment 601602, 1031-1045. doi: 10.1016/j.scitotenv.2017.05.260

Mahmoud, W.H., Elagib, N.A., Gaese H., Heinrich J., 2014. Rainfall conditions and rainwater harvesting potential in the urban area of Khartoum. Resources, Conservation and Recycling 91, 89-99. doi:10.1016/j.resconrec.2014.07.014

Maidment, R., Grimes, D., Allan, R., Tarnavsky, E., Stringer, M., Hewison, T., Roebeling, R., Black, E., 2014. The 30 year TAMSAT African Rainfall Climatology And Time series (TARCAT) data set. Journal of Geophysical Research: Atmospheres 119, 10619-10644. doi:10.1002/2014JD021927 
Maidment, R.I., Grimes, D., Black, E., Tarnavsky, E., Young, M., Greatrex, H., Allan, R.P., Stein, T., Nkonde, E., Senkunda, S., Misael, E., Alcántara, U., 2017. A new, long-term daily satellite-based rainfall dataset for operational monitoring in Africa. Scientific Data 4, 1-19. doi:10.1038/sdata.2017.63

Miao, C., Ashouri, H., Hsu, K.-L., Sorooshian, S., Duan, Q., 2015. Evaluation of the PERSIANN-CDR Daily Rainfall Estimates in Capturing the Behavior of Extreme Precipitation Events over China. Journal of Hydrometeorology 16, 1387-1396. doi:10.1175/JHM-D-14-0174.1

Mohamed, Y.A., Savenije, H.H.G., Bastiaanssen, W.G.M., Van den Hurk, B.J.J.M., 2006. New lessons on the Sudd hydrology learned from remote sensing and climate modeling. Hydrology and Earth System Sciences 10, 507-518.

Nicholson, S.E., 1985. Sub-saharan rainfall 1981-84. Journal of Climate and Applied Meteorology 24(12), 1388-1391.

Novella, N., Thiaw, W., 2013. African rainfall climatology version 2 for famine early warning systems. Journal of Applied Meteorology and Climatology 52, 588-606. doi:10.1175/JAMC-D-11-0238.1

Obled, C., Wendling, J., Beven, K., 1994. The sensitivity of hydrological models to spatial rainfall patterns: an evaluation using observed data. Journal of Hydrology 159(1-4), 305333.

Potter, N., Zhang, L., Milly, P., McMahon, T., Jakeman, A., 2005. Effects of rainfall seasonality and soil moisture capacity on mean annual water balance for Australian catchments. Water Resources Research, 41(6).

Qureshi, S., Khan, N., 1994. Estimation of climatic transition in Riyadh (Saudi Arabia) in global warming perspectives. GeoJournal 33(4), 423-432. 
R Core Team, 2015. R. A Language and Environment for Statistical Computing [WWW Document]. URL at: https://www.R-project.org/ (accessed 27 June 2017).

Rientjes, T., Haile, A.T., Fenta, A.A., 2013. Diurnal rainfall variability over the Upper Blue Nile Basin: A remote sensing based approach. International Journal of Applied Earth Observation and Geoinformation, 21, 311-325.

Roca, R., Chambon, P., Jobard, I., Kirstetter, P., Gosset, M., Bergés, J., 2010. Comparing satellite and surface rainfall products over West Africa at meteorologically relevant scales during the AMMA campaign using error estimates. Journal of Applied Meteorology and Climatology 49, 715-731.

Romilly, T.G., Gebremichael, M., 2011. Evaluation of satellite rainfall estimates over Ethiopian river basins. Hydrology and Earth System Sciences, 15(5), 1505-1514.

Salman, S.M.A., 2011. The new state of South Sudan and the hydro-politics of the Nile Basin. Water Internationaln36, 154-166. doi:10.1080/02508060.2011.557997

Schneider, U., Becker, A., Finger, P., Meyer-Christoffer, A., Rudolf, B., Ziese, M., 2015. Monthly Land-Surface GPCC Full Data Reanalysis Version 7.0 at $0.5^{\circ}$ : Monthly LandSurface Precipitation from Rain-Gauges built on GTS-based and Historic Data [WWW Document]. doi:10.5676/DWD_GPCC/FD_M_V7_050

Schneider, U., Ziese, M., Meyer-christoffer, A., Finger, P., Rustemeier, E., Becker, A., 2016. The new portfolio of global precipitation data products of the Global Precipitation Climatology Centre suitable to assess and quantify the global water cycle and resources. Proc. IAHS 29-34. doi:10.5194/piahs-374-29-2016

Sutcliffe, J., Parks, Y., 1999. The Hydrology of the Nile, IAHS Special Publication. The International Association of Hydrological Science, Wallingford.

Serrat-Capdevila, A., Merino, M., Valdes, J., Durcik, M., 2016. Evaluation of the performance of three satellite precipitation products over Africa. Remote Sensing 8, 836 . 
Tall, A., 2010. Climate forecasting to serve communities in West Africa. Procedia Environmental Sciences 1, 421-431.

Tarnavsky, E., Grimes, D., Maidment, R., Black, E., Allan, R.P., Stringer, M., Chadwick, R., Kayitakire, F., 2014. Extension of the TAMSAT satellite-based rainfall monitoring over Africa and from 1983 to present. Journal of Applied Meteorology and Climatology 53(12), 2805-2822.

Thiemig, V., Rojas, R., Zambrano-Bigiarini, M., Levizzani, V., De Roo, A., 2012. Validation of Satellite-Based Precipitation Products over Sparsely Gauged African River Basins. Journal of Hydrometeorology 13, 1760-1783.

Thomson, M.C., Connor, S.J., Zebiak, S.E., Jancloes, M., Mihretie, A., 2011. Africa needs climate data to fight disease. Nature 471(7339), 440-442.

Washington, R., Kay, G., Harrison, M., Conway, D., Black, E., Challinor, A., Grimes, D., Jones, R., Morse, A., Todd, M., 2006. African climate change: taking the shorter route. Bulletin of the American Meteorological Society 87(10), 1355-1366.

Wheeler, K., Basheer, M., Mekonnen, Z., Eltoum, S., Mersha, A., Abdo, G., Zagona, E., Hall, J., Dadson, S., 2016. Cooperative filling approaches for the Grand Ethiopian Renaissance Dam. Water International 8060, 1-24. doi:10.1080/02508060.2016.1177698

Worqlul, A.W., Maathuis, B., Adem, A.A., Demissie, S.S., Langan, S., Steenhuis, T.S., 2014. Comparison of rainfall estimations by TRMM 3B42, MPEG and CFSR with groundobserved data for the Lake Tana basin in Ethiopia. Hydrology and Earth System Sciences 18(12), 4871-4881.

Young, M., Williams, C., Chiu, J., Maidment, R., Chen, S., 2014. Investigation of discrepancies in satellite rainfall estimates over Ethiopia. Journal of Hydrometeorology 15, 2347-2369. 


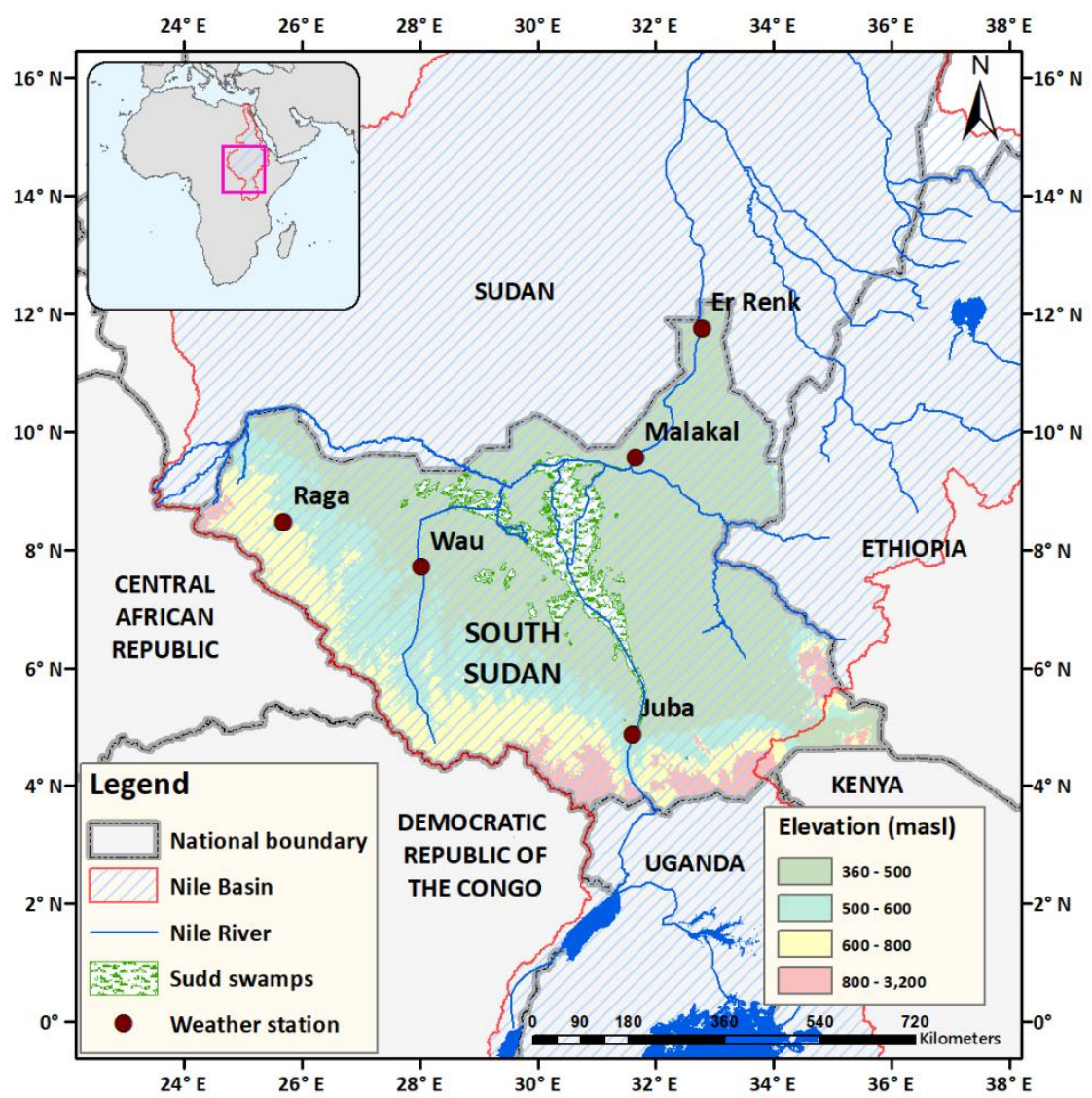

Fig. 1. Topography, rainfall stations, and general features of the study area. 

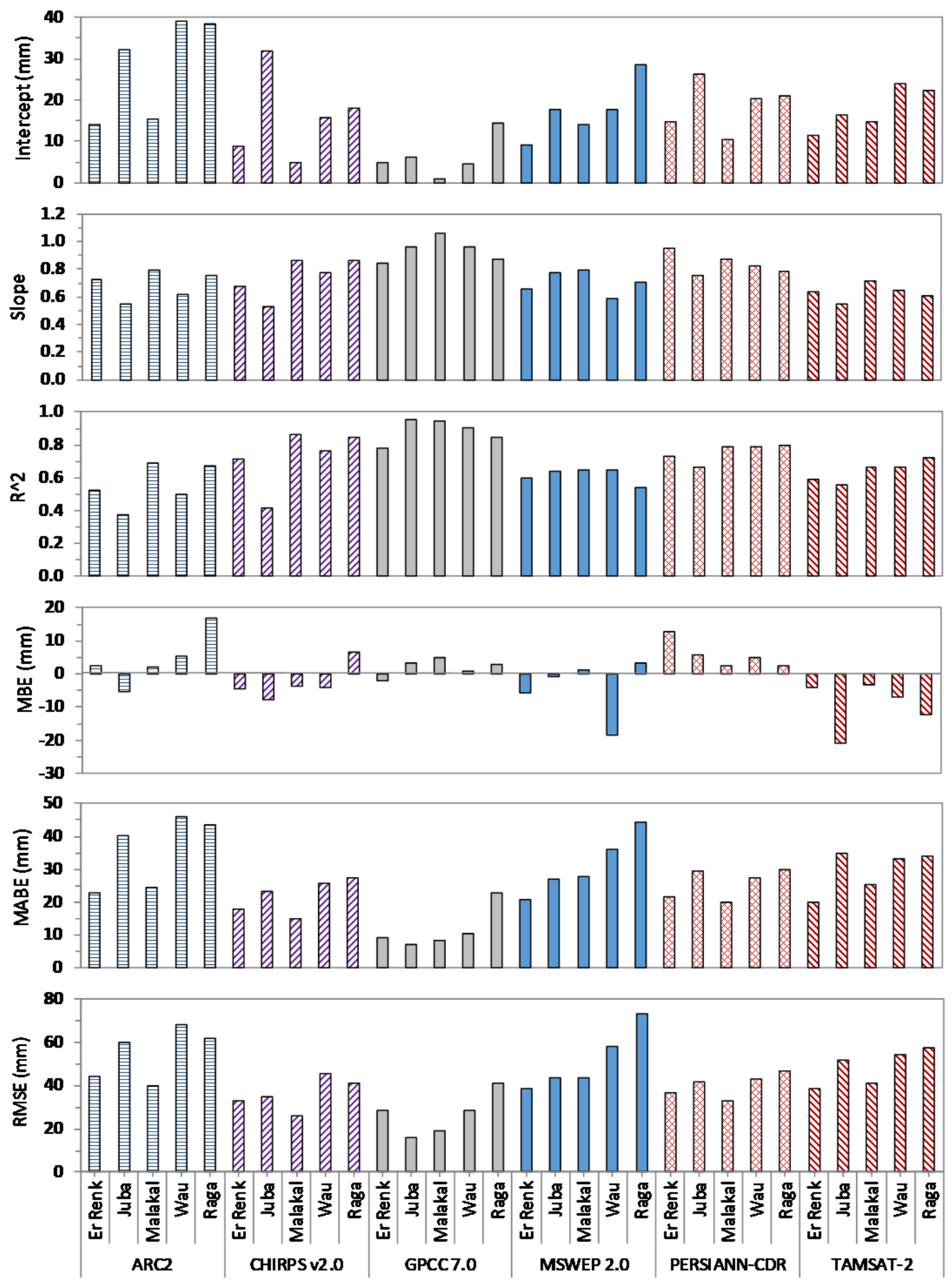

Fig. 2. Performance metrics of all products of monthly rainfall as evaluated at five stations. 

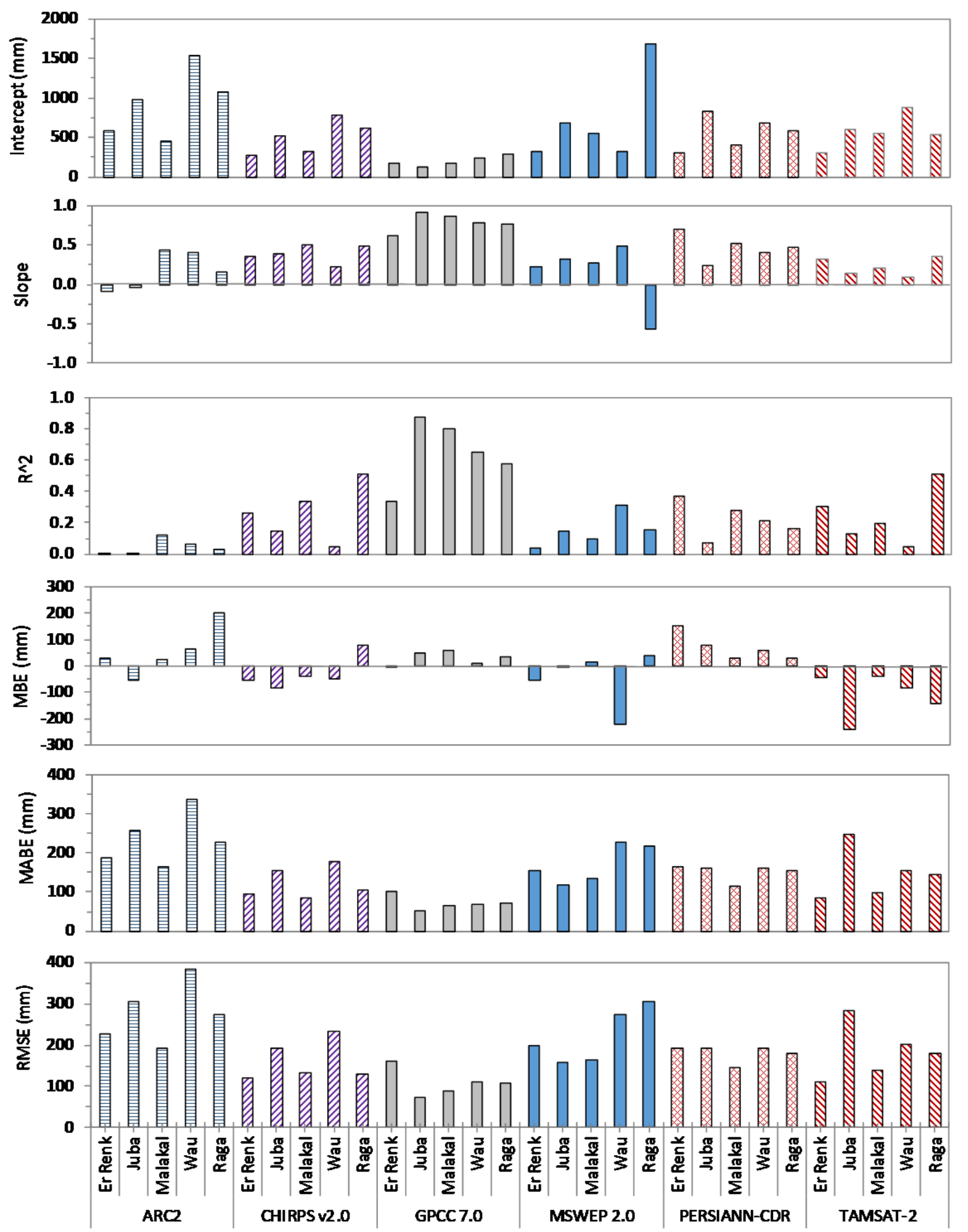

Fig. 3. Performance metrics of all products of annual rainfall as evaluated at five stations. 

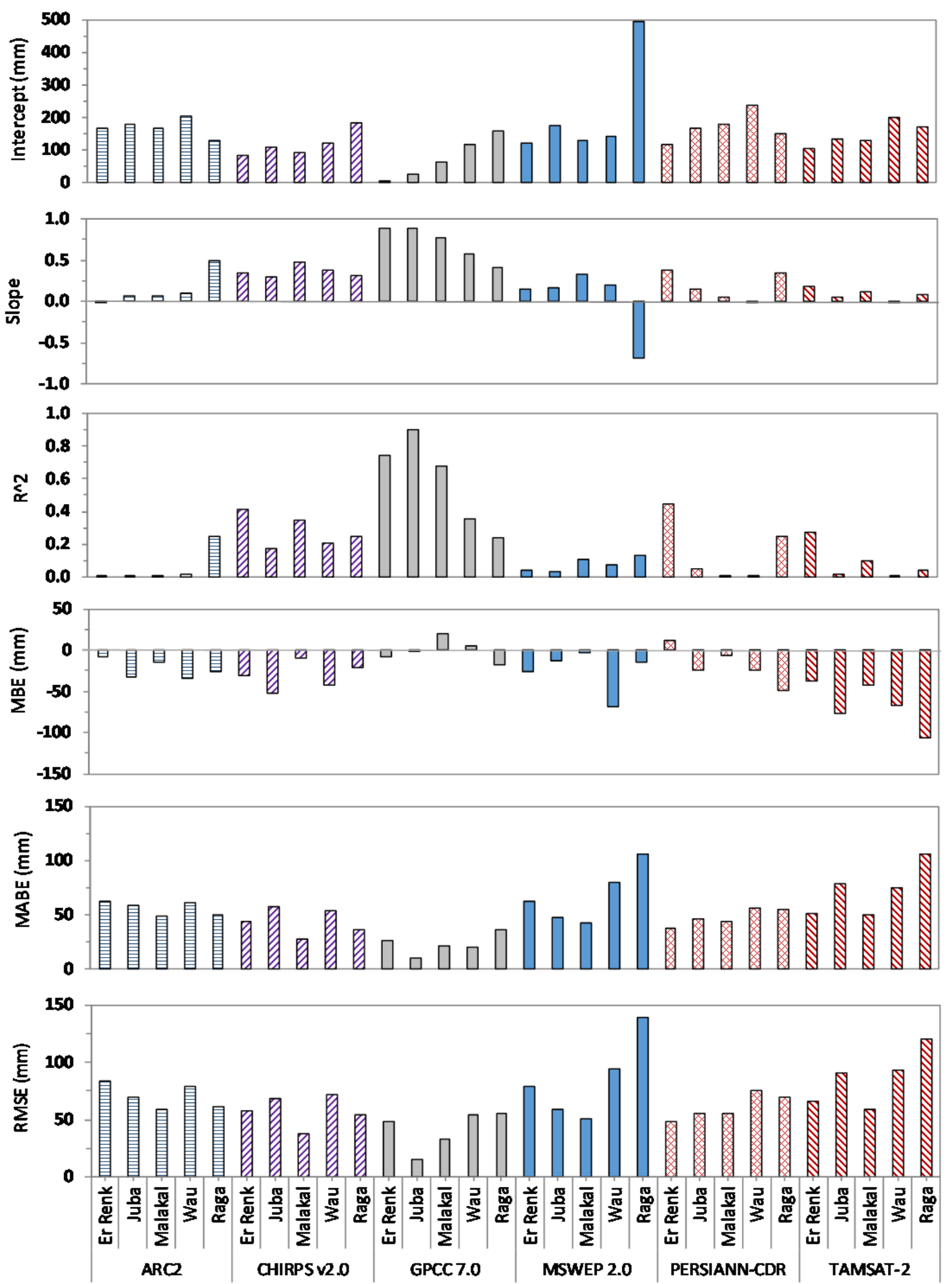

Fig. 4. Performance metrics of all products of maximum monthly rainfall as evaluated at five stations 

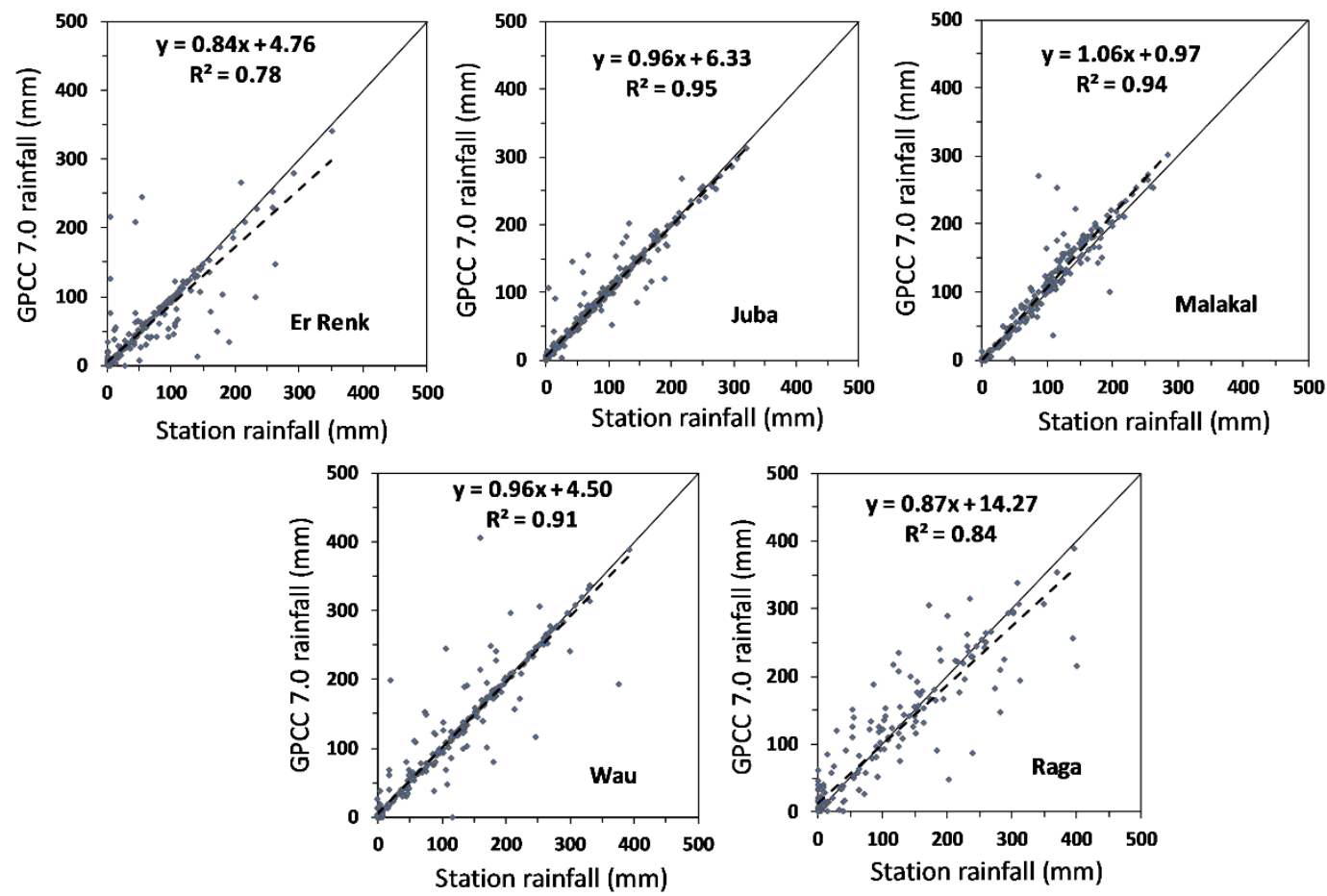

(a)
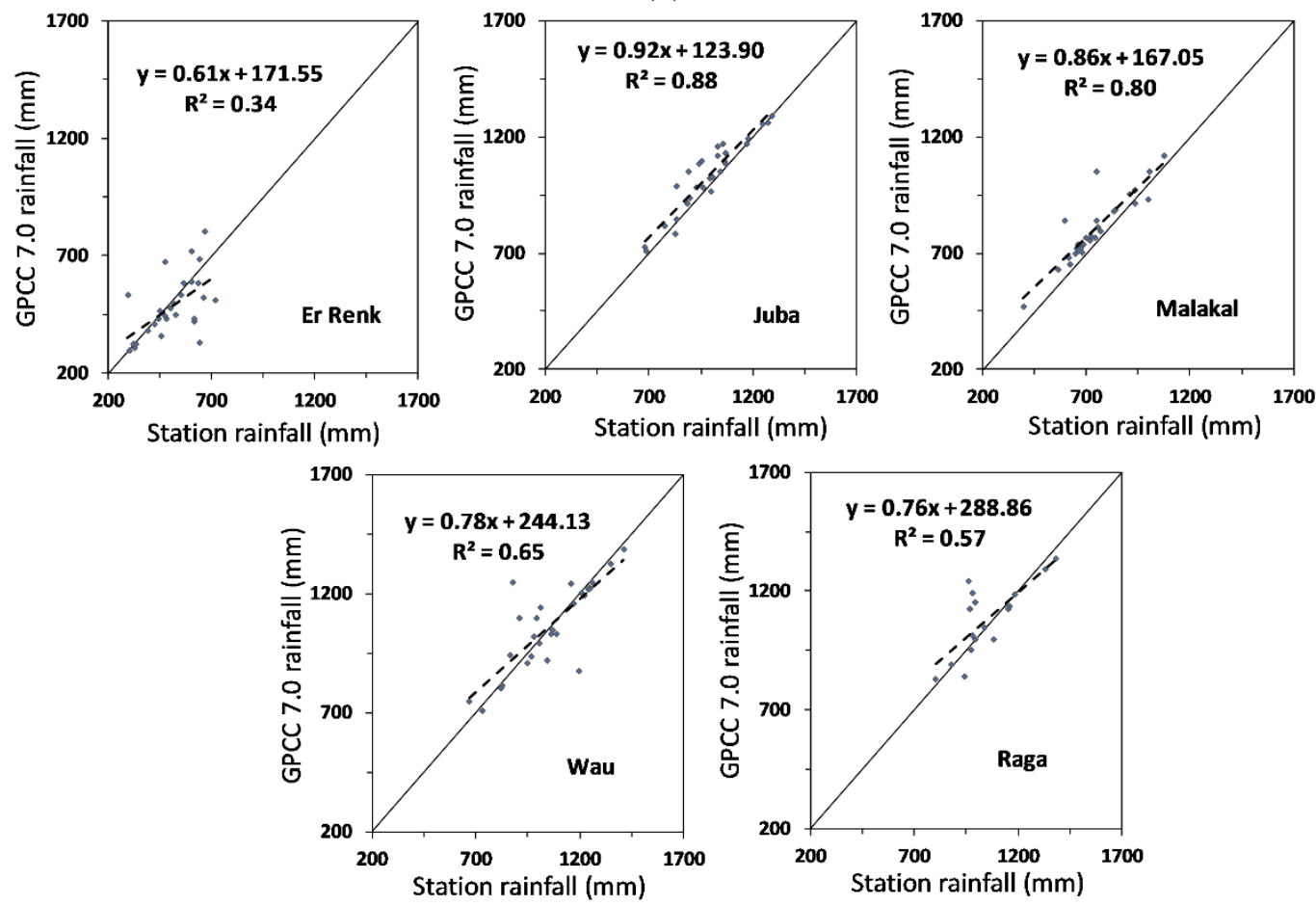

(b)

Fig. 5. Scatterplot of (a) monthly, (b) annual and (c) maximum monthly rainfalls from GPCC 7.0 versus ground stations. The continuous and dotted lines represent the $1: 1$ and regression lines, respectively. All $R$ values are significant to (a) $p<0.001$, (b) $p=0.001$ and (c) $p=$ 0.001 , except for Raga $\mathrm{p}=0.046$. 

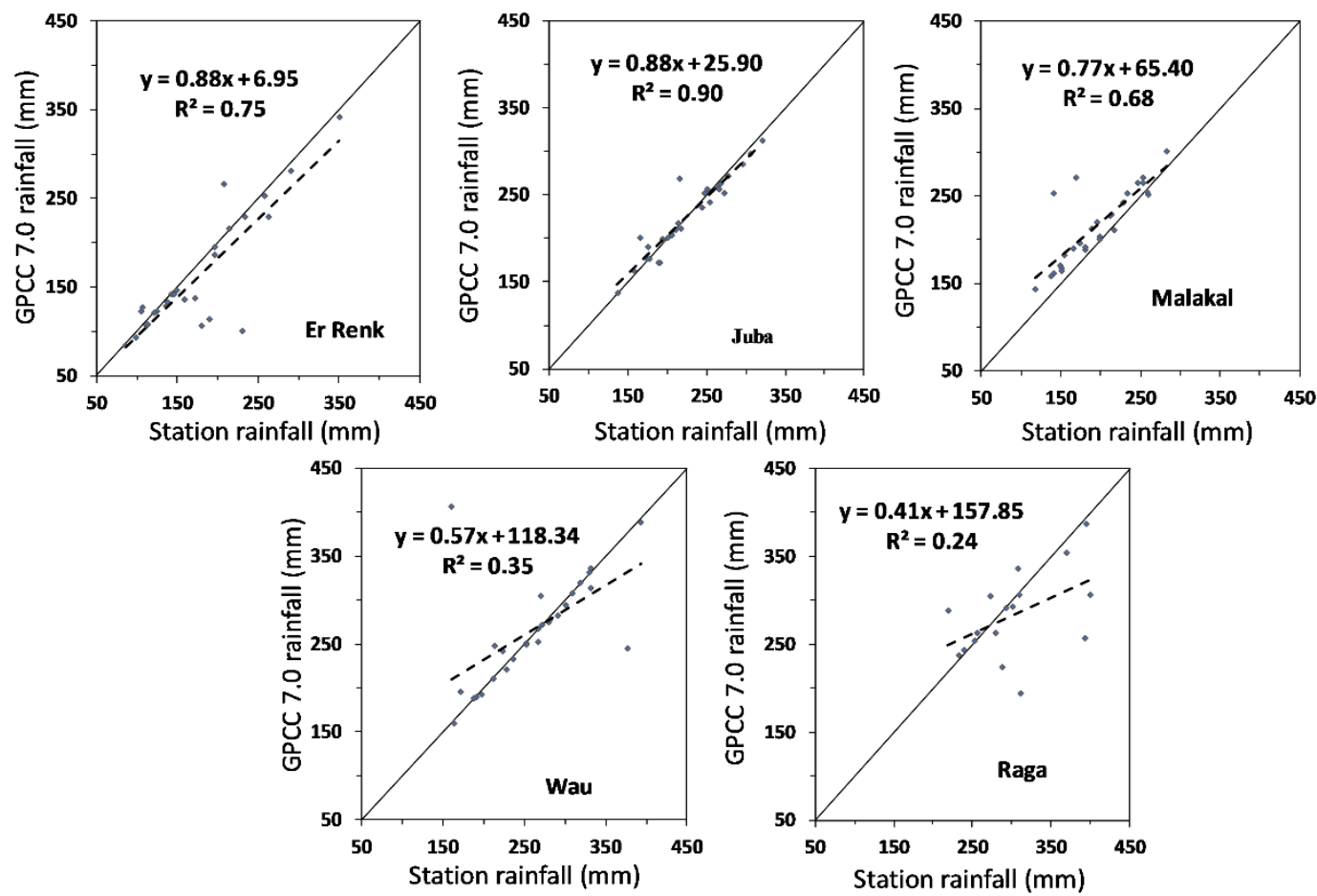

(c)

Fig. 5. (Continued). 


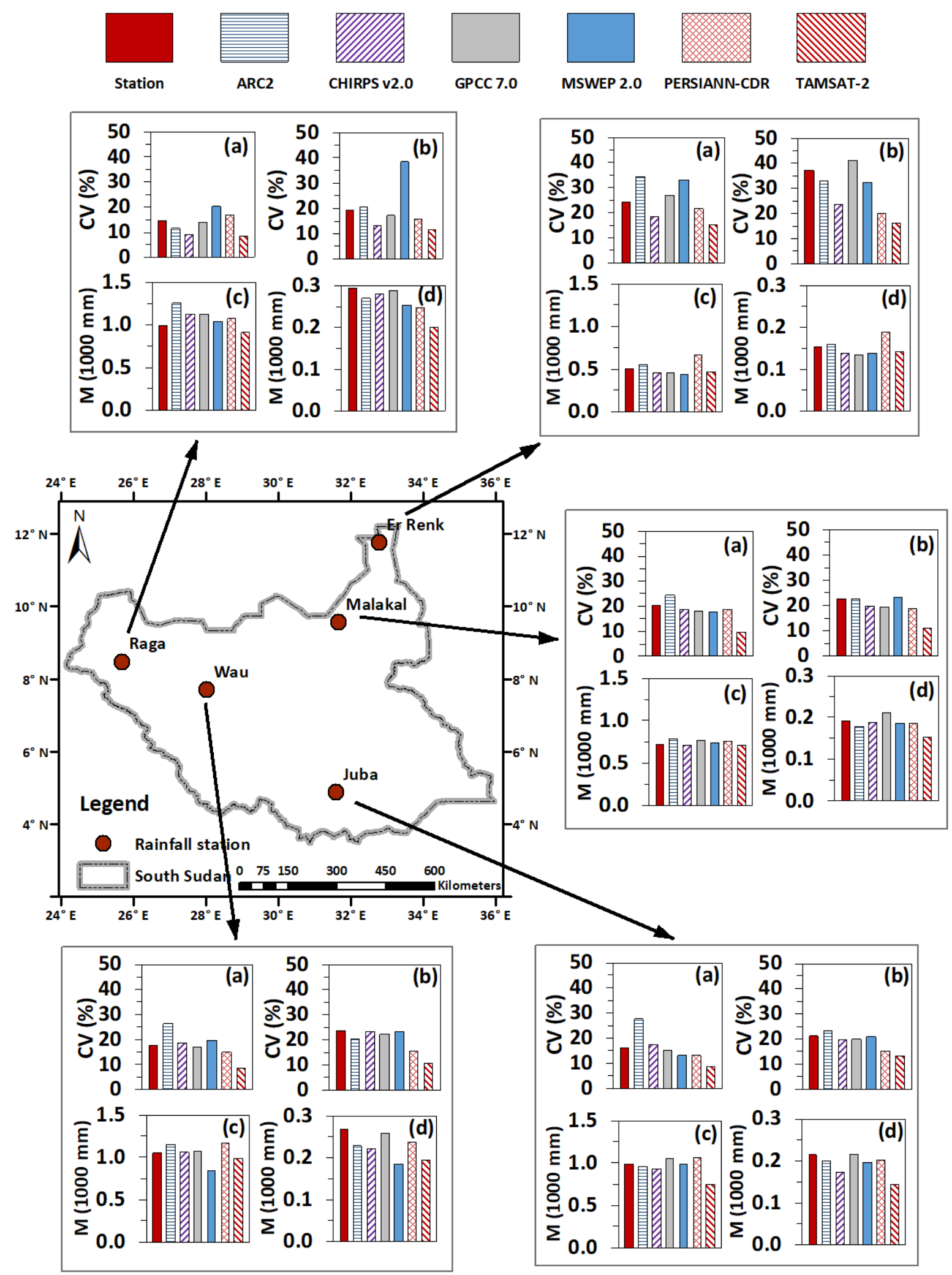

Fig. 6. Coefficient of Variation (CV) and Median (M) for the station and satellite rainfalls:

(a) coefficient of variation of annual rainfall, (b) coefficient of variation of maximum monthly rainfall, (c) median annual rainfall and (d) median maximum monthly rainfall. 


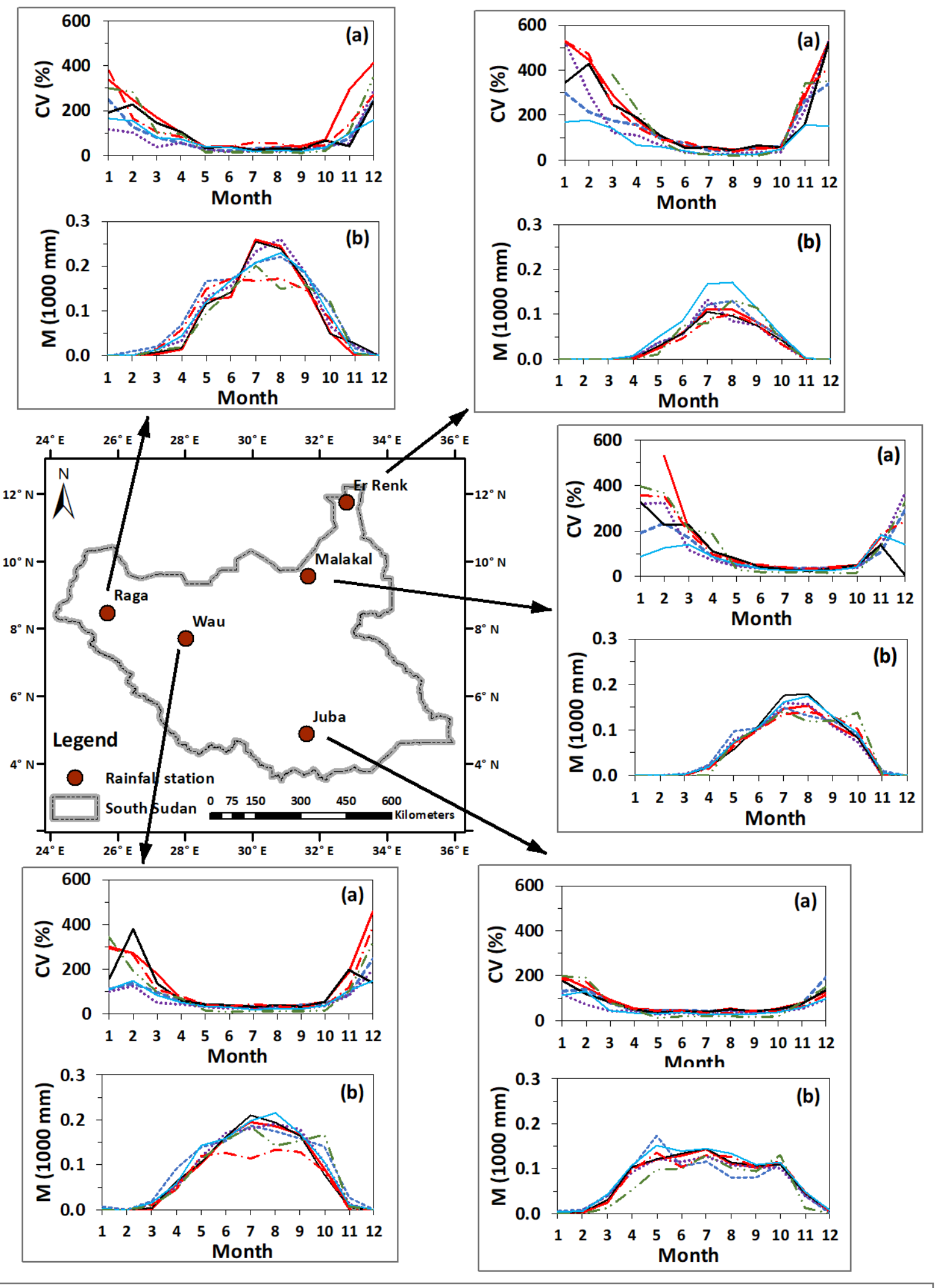

- Station --- ARC2 …... CHIRPS v 2.0 - GPCC $7.0-\cdots$ MSWEP 2.0 - PERSIANN-CDR - . TAMSAT-2

Fig. 7. Coefficient of Variation (CV) and Median (M) for the station and satellite rainfalls: (a) coefficient of variation of monthly rainfall and (b) median monthly rainfall. 
Table 1. Ranking of the rainfall products for each station based on the unified metric (UM) and the overall unified metric (OUM). See text for description of the metrics.

\begin{tabular}{llllllll}
\hline Rainfall & Product & El Renk & Juba & Malakal & Wau & Raga & OUM \\
\cline { 3 - 7 } & & \multicolumn{7}{c}{ UM } & UM & \\
\hline Monthly & ARC2 & 28 & 32 & 25 & 33 & 32 & 150 \\
& CHIRPS v 2.0 & 17 & 25 & 16 & 15 & 13 & 86 \\
& GPCC 7.0 & 7 & 7 & 11 & 6 & 8 & 39 \\
& MSWEP 2.0 & 25 & 16 & 27 & 30 & 30 & 128 \\
& PERSIANN-CDR & 23 & 20 & 17 & 16 & 16 & 92 \\
& TAMSAT-2 & 26 & 26 & 30 & 26 & 27 & 135 \\
Annual & ARC2 & 32 & 36 & 27 & 30 & 34 & 159 \\
& CHIRPS v 2.0 & 17 & 15 & 16 & 25 & 17 & 90 \\
& GPCC 7.0 & 12 & 7 & 11 & 6 & 7 & 43 \\
& MSWEP 2.0 & 29 & 18 & 27 & 22 & 27 & 123 \\
& PERSIANN-CDR & 20 & 27 & 19 & 16 & 19 & 101 \\
& TAMSAT-2 & 16 & 23 & 26 & 27 & 22 & 114 \\
Maximum & ARC2 & 32 & 31 & 30 & 24 & 14 & 131 \\
& CHIRPS v 2.0 & 19 & 19 & 13 & 14 & 19 & 84 \\
& GPCC 7.0 & 6 & 6 & 9 & 6 & 15 & 42 \\
& MSWEP 2.0 & 29 & 20 & 16 & 27 & 25 & 117 \\
& PERSIANN-CDR & 15 & 18 & 28 & 26 & 21 & 108 \\
& TAMSAT-2 & 25 & 32 & 30 & 29 & 32 & 148 \\
\hline
\end{tabular}


Performance of satellite-based and GPCC 7.0 rainfall products in an extremely datascarce country in the Nile Basin

\section{Supplementary material}

Mohammed Basheer ${ }^{1,2}$ and Nadir Ahmed Elagib ${ }^{1 *}$

${ }^{1}$ Institute for Technology and Resources Management in the Tropics and Sub-tropics (ITT),

Technische Hochschule Köln, Betzdorferstr. 2, 50679, Cologne, Germany

*Corresponding author's emails: elagib@hotmail.com; nadir.elagib@th-koeln.de

${ }^{2}$ Email addresses: mohammedadamabbaker@gmail.com; mohammed.basheer@th-koeln.de 

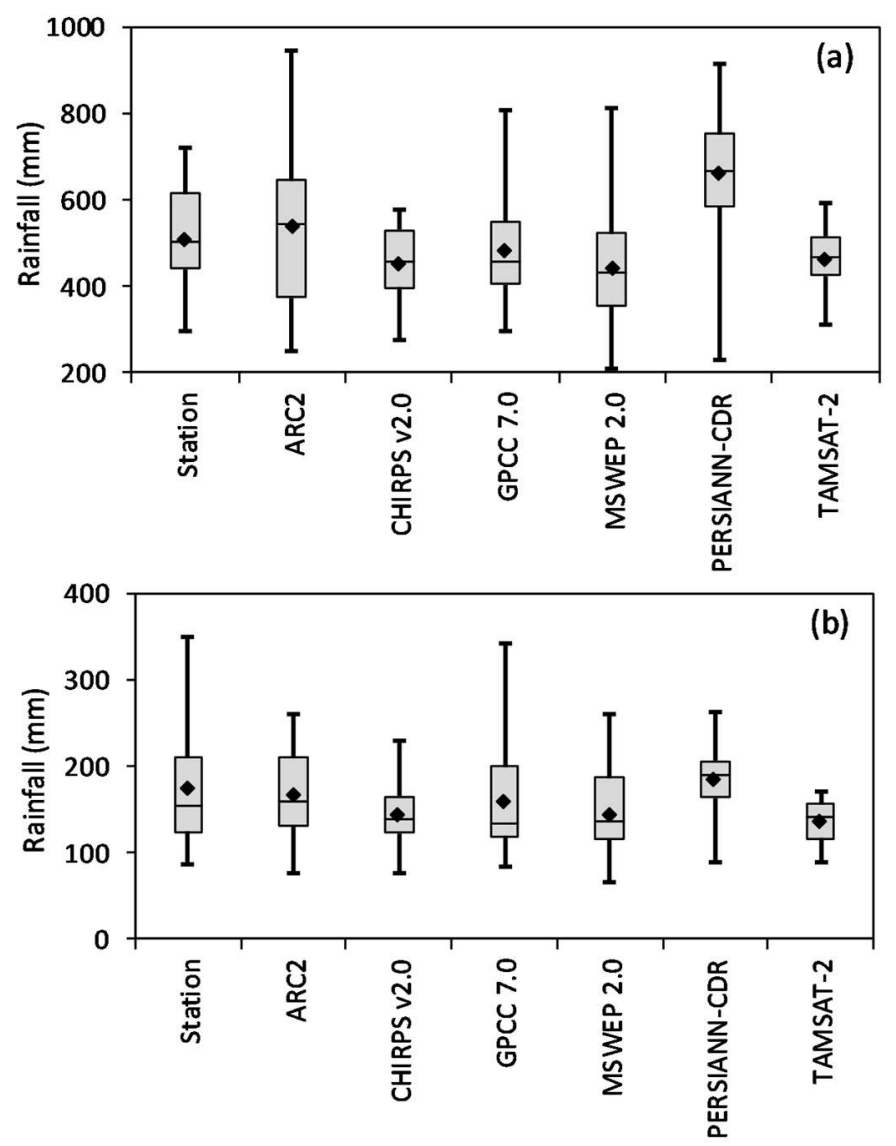

Fig.S1 Boxplots for Er Renk station for the period 1983 to 2010: (a) annual rainfall (b) maximum monthly rainfall. The black dots indicate the mean. 
Performance of satellite-based and GPCC 7.0 rainfall products in an extremely data-scarce country in the Nile Basin
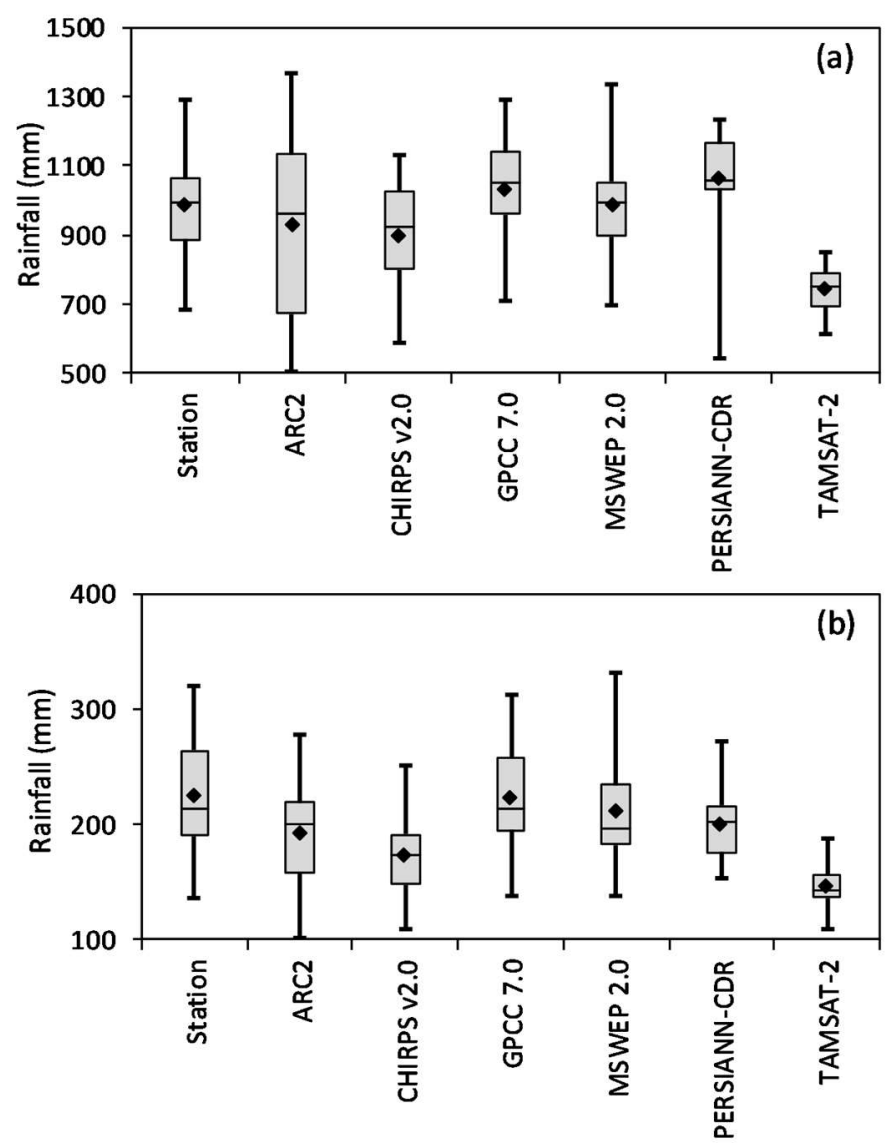

Fig.S2 Boxplots for Juba station for the period 1983 to 2010: (a) annual rainfall (b) maximum monthly rainfall. The black dots indicate the mean. 
Performance of satellite-based and GPCC 7.0 rainfall products in an extremely data-scarce country in the Nile Basin
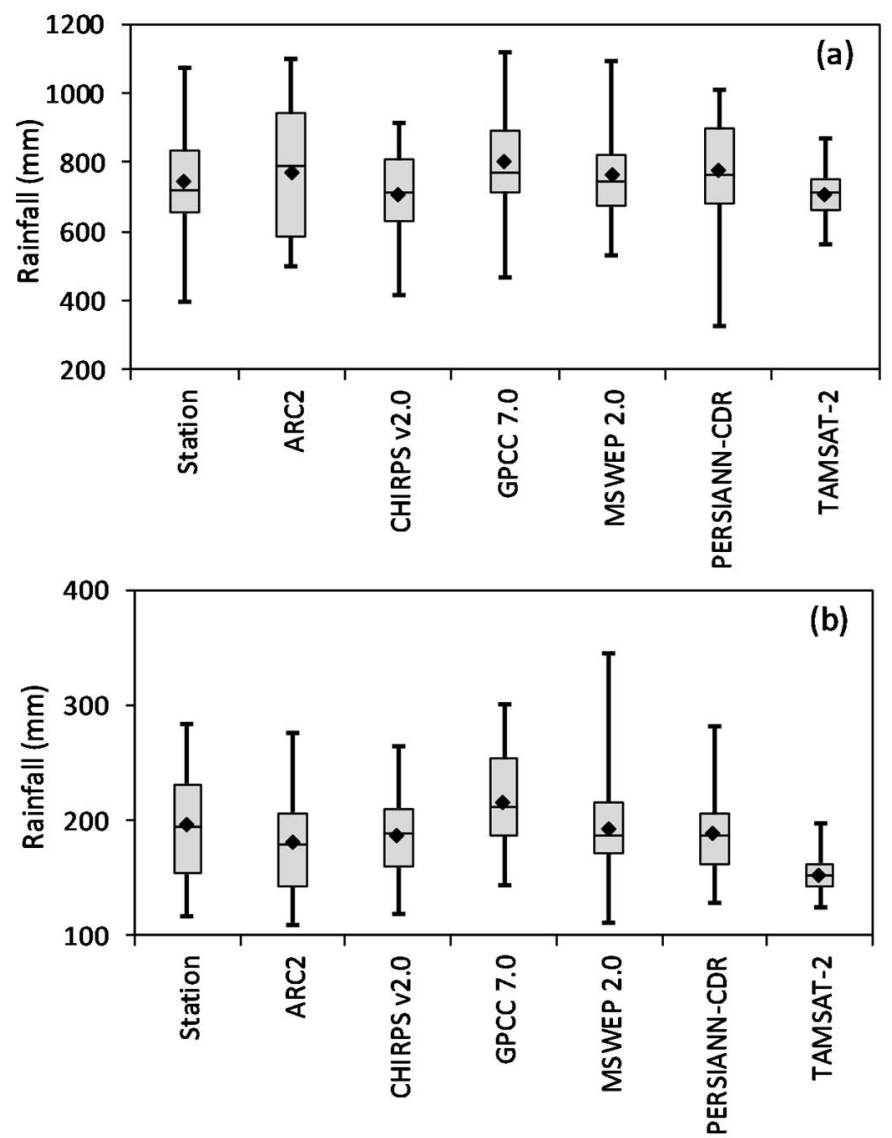

Fig.S3 Boxplots for Malakal station for the period 1983 to 2010: (a) annual rainfall (b) maximum monthly rainfall. The black dots indicate the mean. 
Performance of satellite-based and GPCC 7.0 rainfall products in an extremely data-scarce country in the Nile Basin
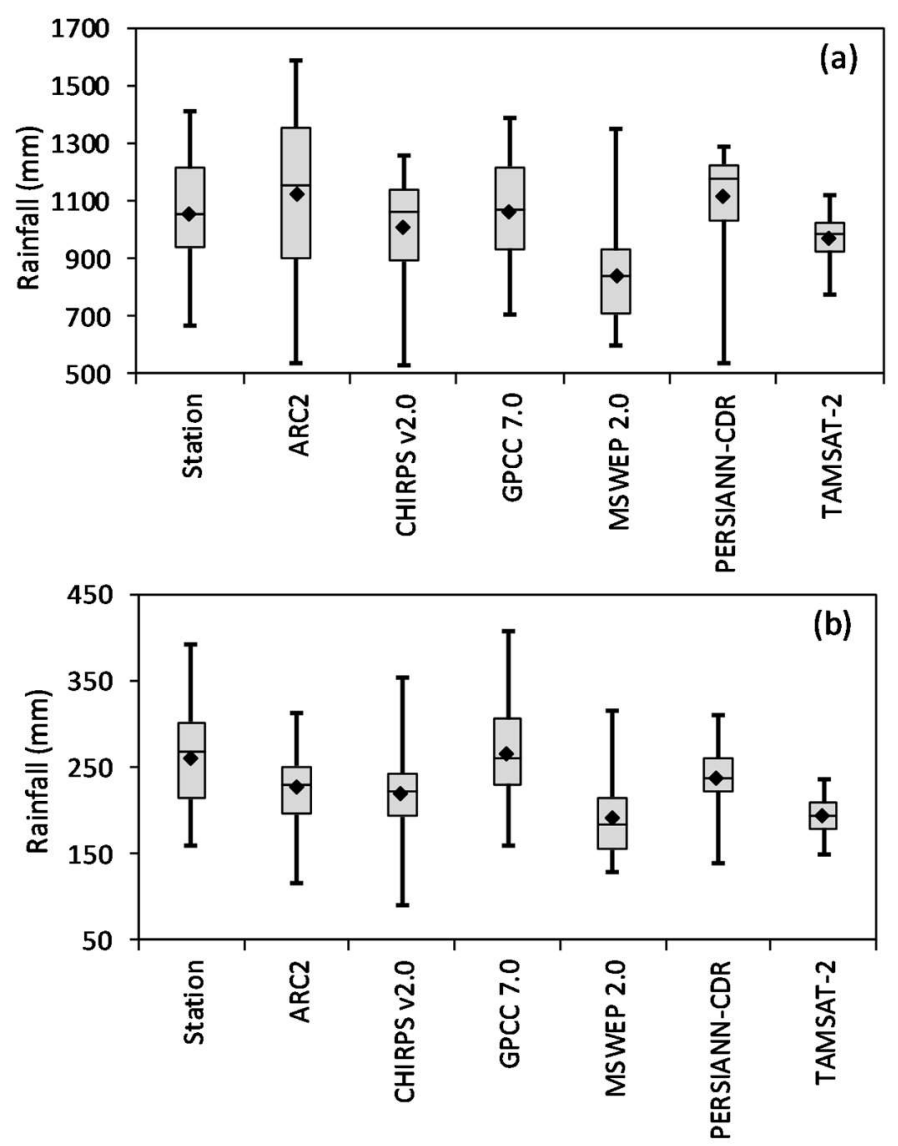

Fig.S4 Boxplots for Wau station for the period 1983 to 2010: (a) annual rainfall (b) maximum monthly rainfall. The black dots indicate the mean. 
Performance of satellite-based and GPCC 7.0 rainfall products in an extremely data-scarce country in the Nile Basin

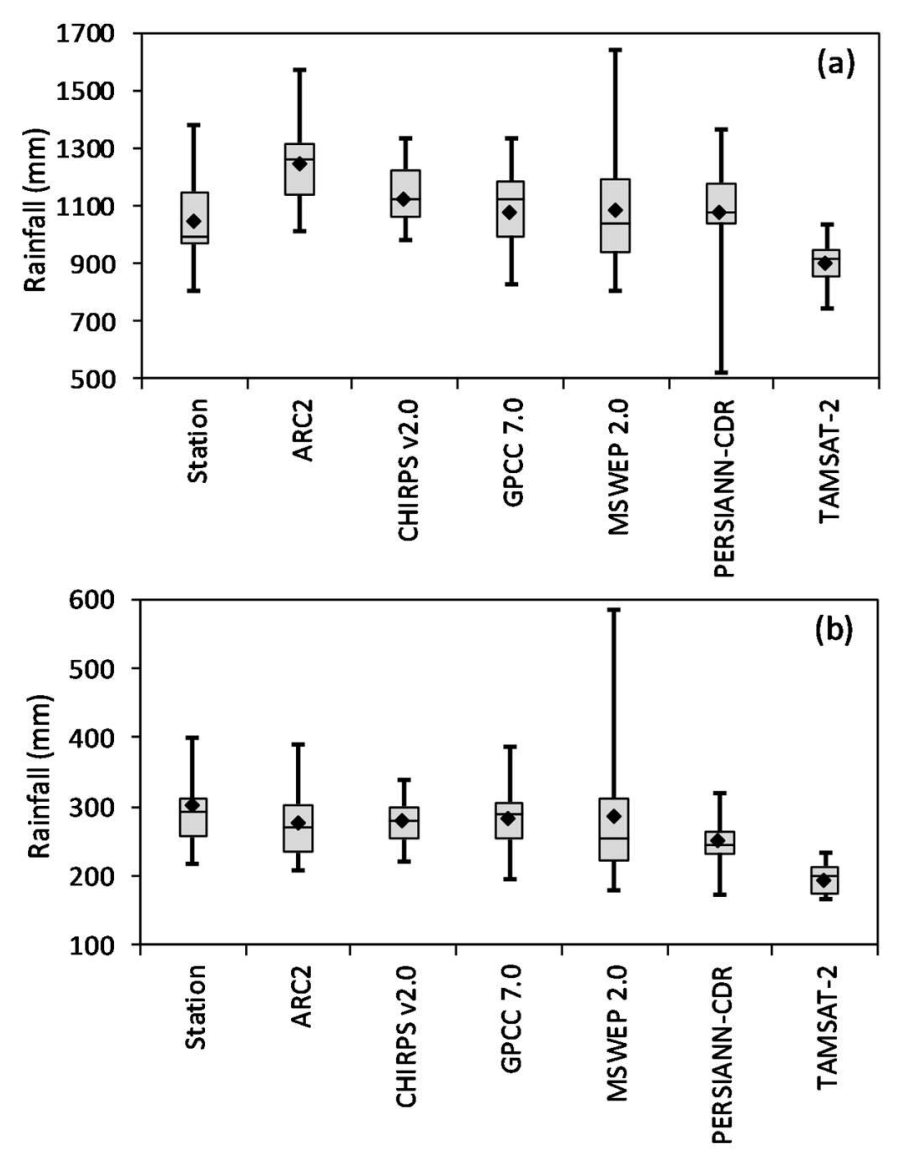

Fig.S5 Boxplots for Raga station for the period 1983 to 1999: (a) annual rainfall (b) maximum monthly rainfall. The black dots indicate the mean. 
Performance of satellite-based and GPCC 7.0 rainfall products in an extremely data-scarce country in the Nile Basin
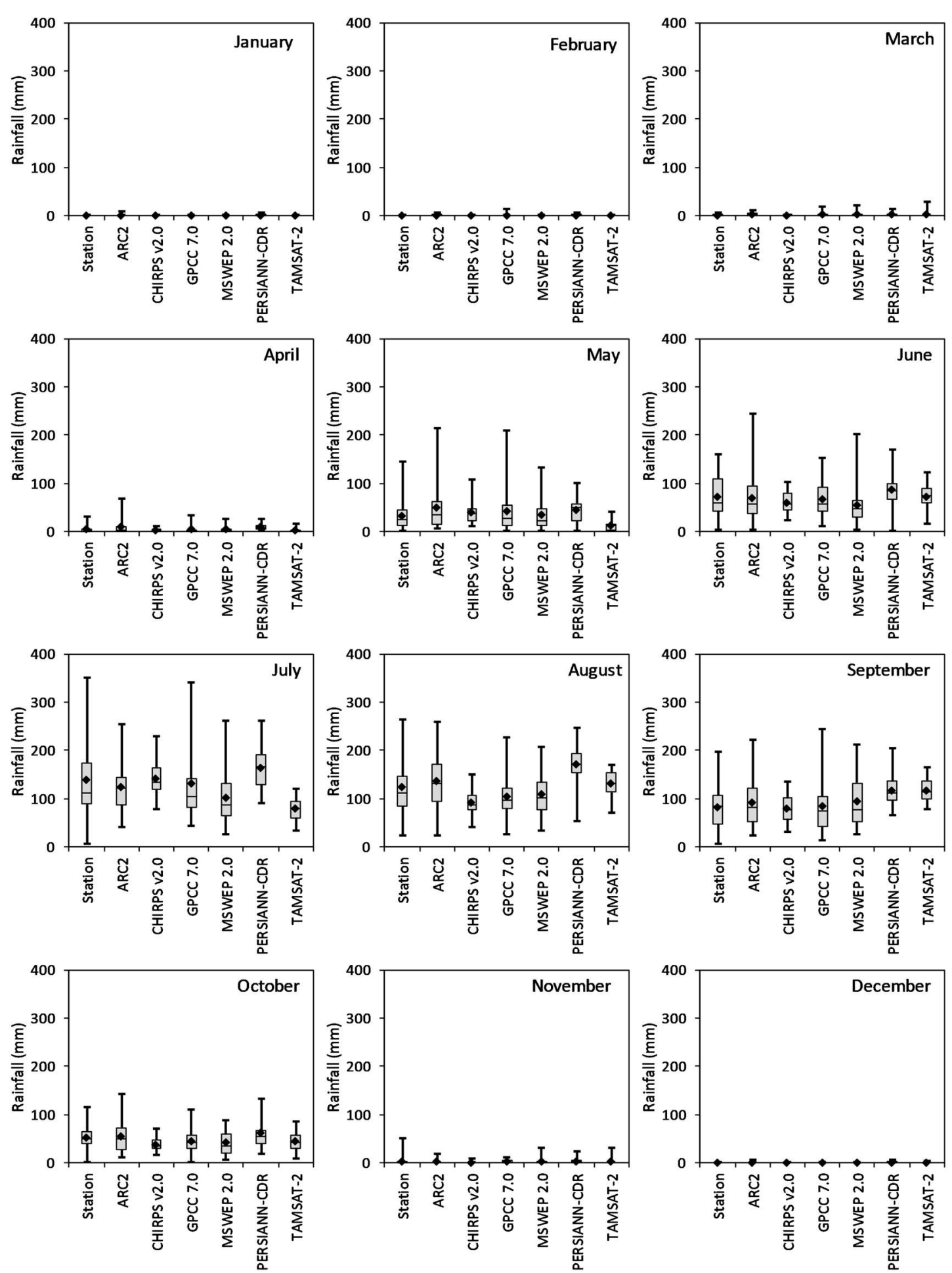

Fig.S6 Boxplots of monthly rainfall for Er Renk station for the period 1983 to 2010. The black dots indicate the mean. 
Performance of satellite-based and GPCC 7.0 rainfall products in an extremely data-scarce country in the Nile Basin
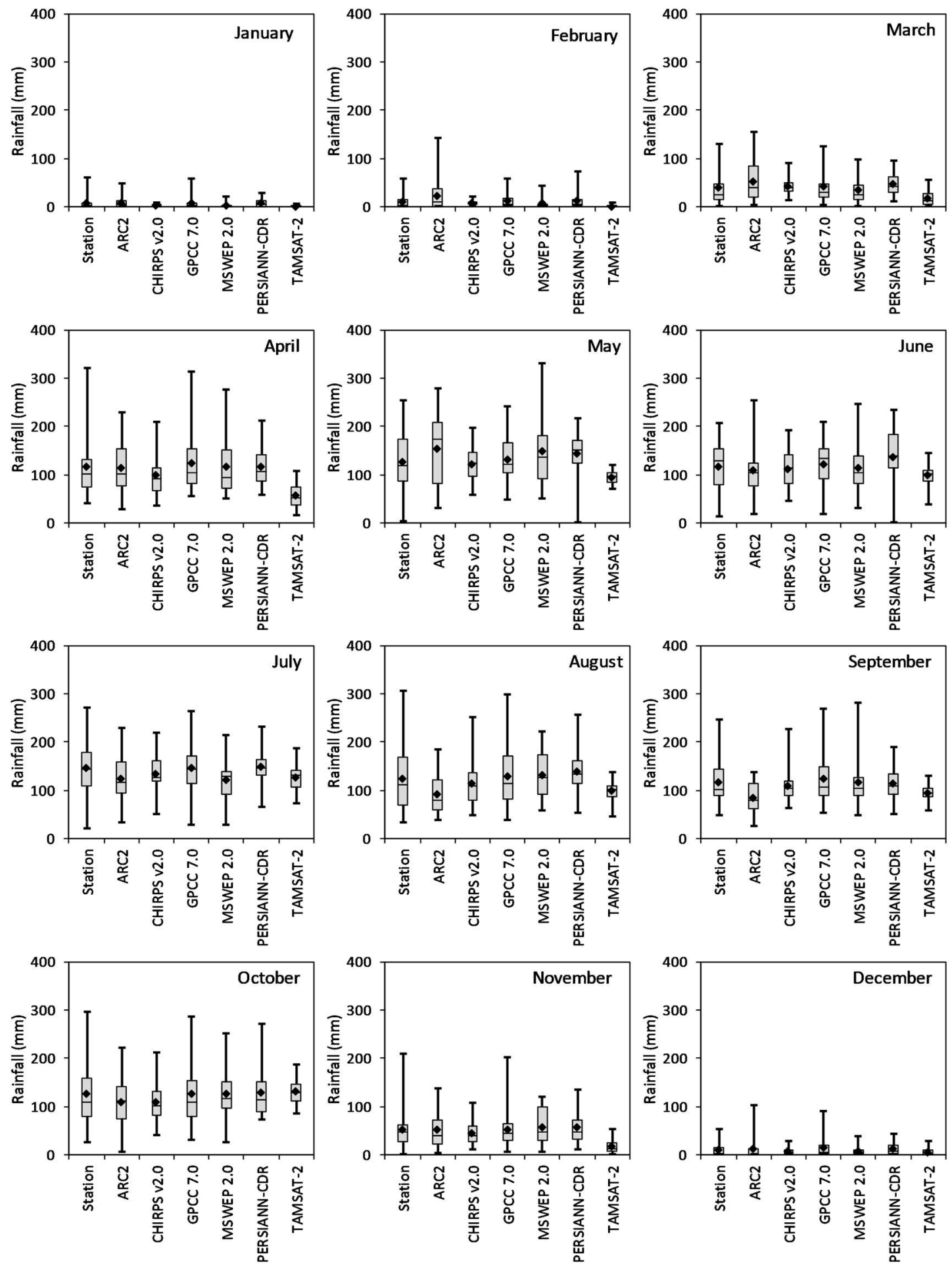

Fig.S7 Boxplots of monthly rainfall for Juba station for the period 1983 to 2010 . The black dots indicate the mean. 
Performance of satellite-based and GPCC 7.0 rainfall products in an extremely data-scarce country in the Nile Basin
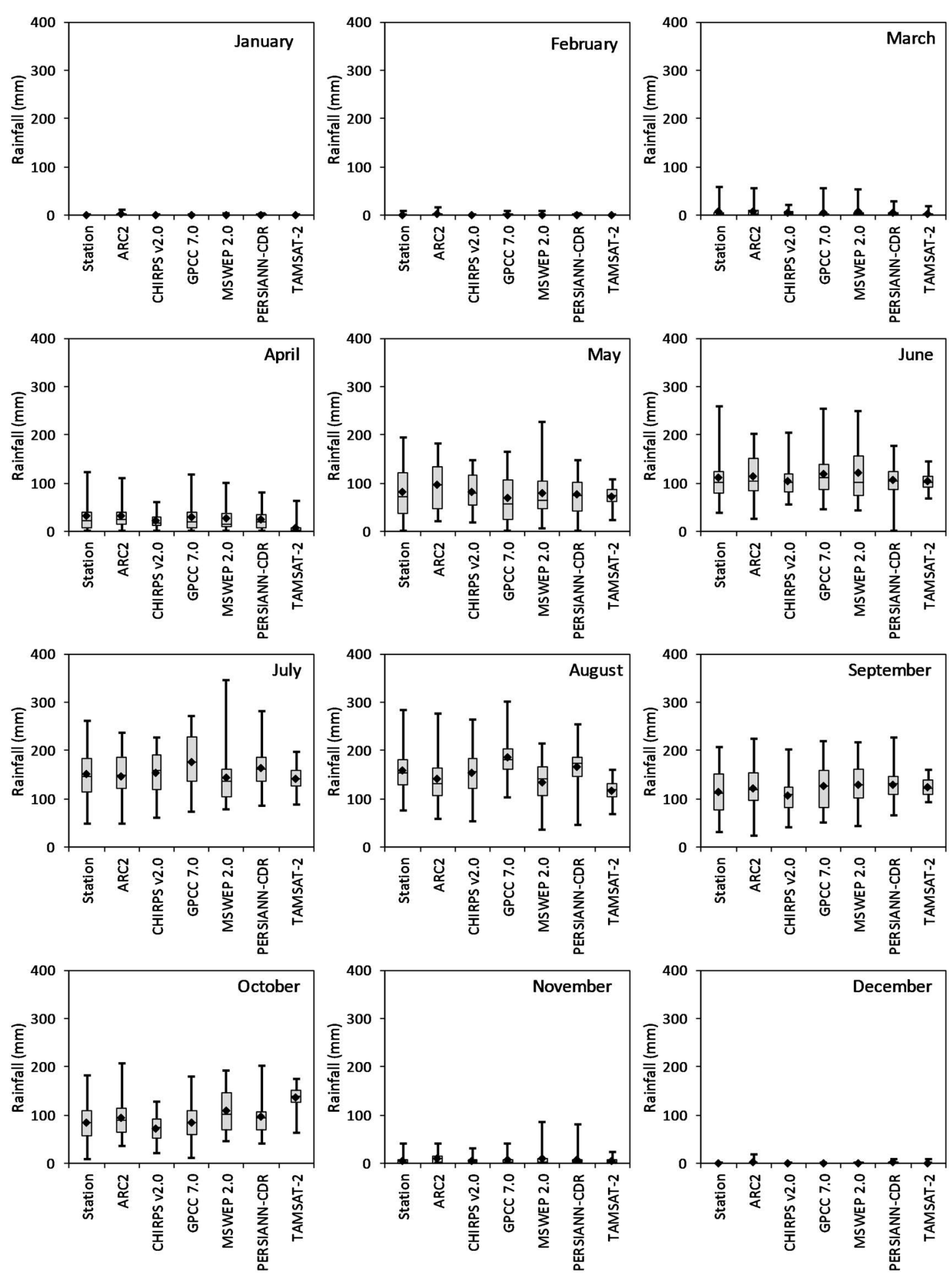

Fig.S8 Boxplots of monthly rainfall for Malakal station for the period 1983 to 2010. The black dots indicate the mean. 
Performance of satellite-based and GPCC 7.0 rainfall products in an extremely data-scarce country in the Nile Basin
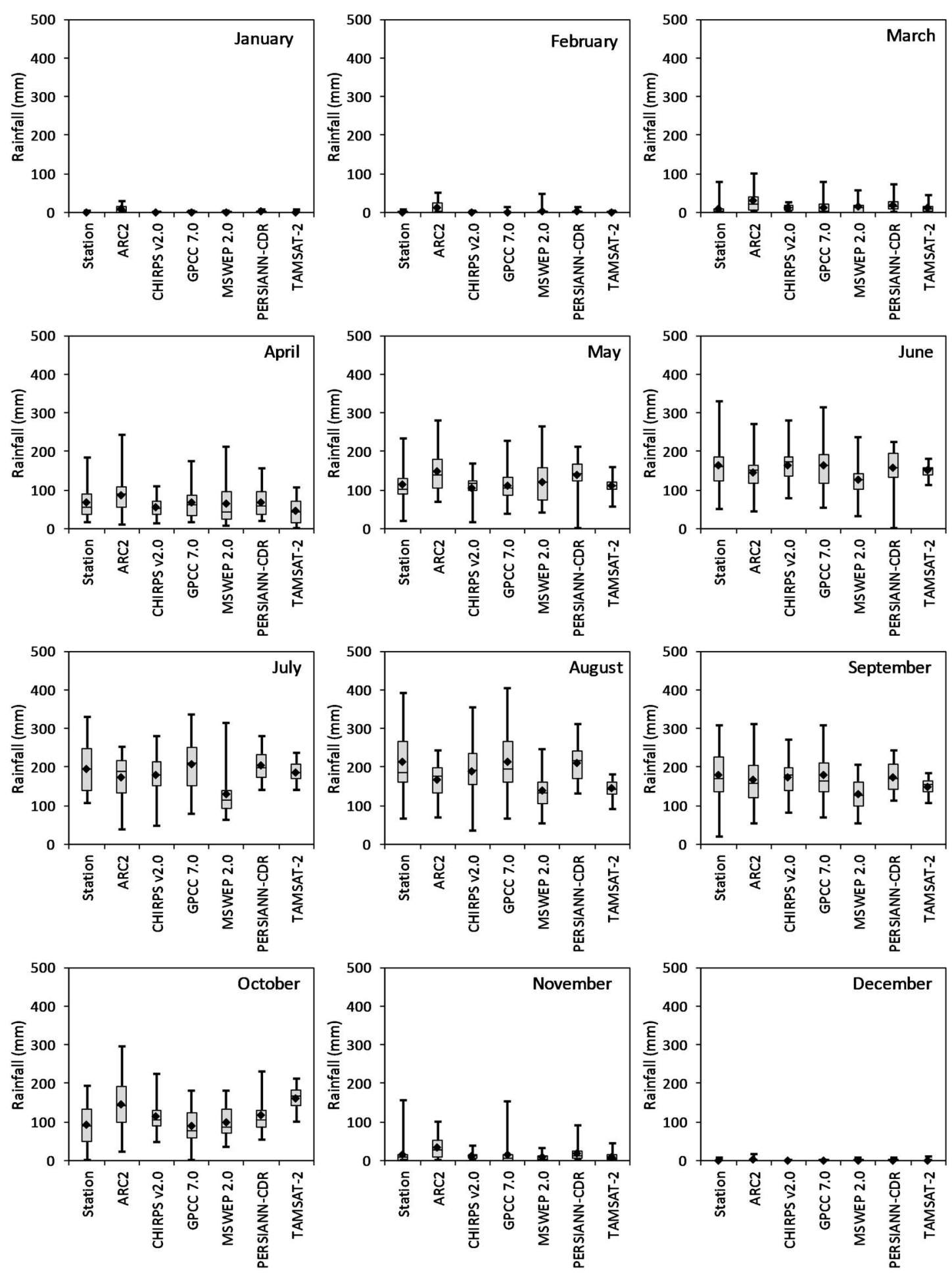

Fig.S9 Boxplots of monthly rainfall for Wau station for the period 1983 to 2010 . The black dots indicate the mean. 
Performance of satellite-based and GPCC 7.0 rainfall products in an extremely data-scarce country in the Nile Basin
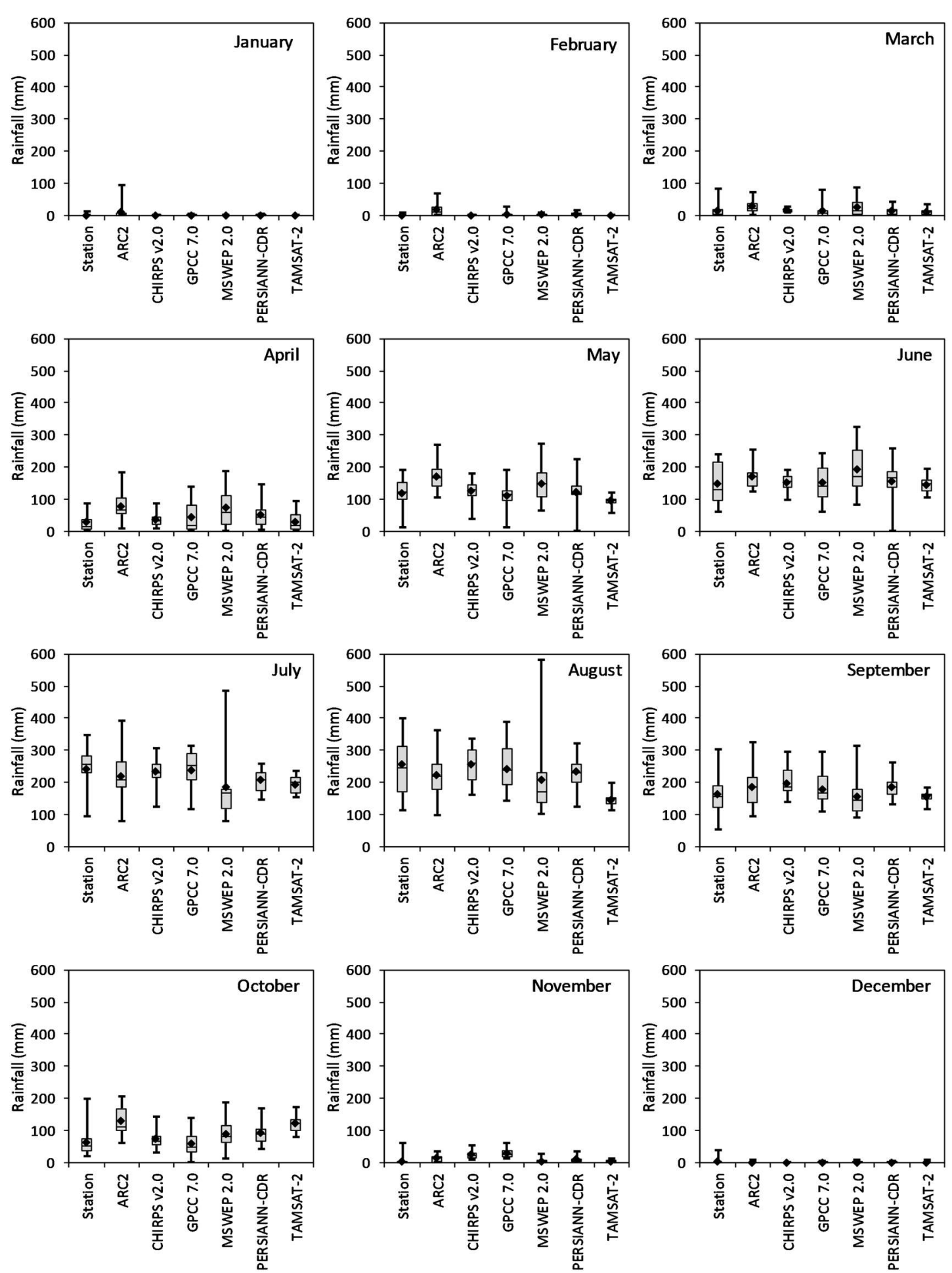

Fig.S10 Boxplots of monthly rainfall for Raga station for the period 1983 to 1999 . The black dots indicate the mean. 